\title{
Revisión de los conceptos de acción, omisión y comisión por omisión. Un análisis a través de casos
}

\author{
Review of the concepts of action, \\ omission and commission by omission. \\ An analysis through cases
}

VIRGiLIo RodríGuez Vázouez'

\section{Resumen}

En este trabajo se estudian los distintos conceptos de acción, omisión y comisión por omisión. Se valora si esta distinción tiene importancia o no y se explica la regulación que contiene el CP español. Finalmente, se estudian estas cuestiones a través del análisis de casos.

\section{Palabras clave}

Acción, omisión, Código penal, casos prácticos.

1 Profesor Contratado Doctor de Derecho Penal (Acreditado Profesor Titular) de la Universidad de Vigo Facultad de Derecho. Campus Universitario. Universidad de Vigo. 32004 Ourense.

Contacto: virxilio@uvigo.es; virxilio.webs.uvigo.es

El presente trabajo se inscribe en el proyecto de investigación "Responsabilidad penal de personas físicas y jurídicas en el ámbito empresarial, económico, laboral y de los mercados (II)" (Referencia: DER201458546-R, Ministerio de Economía y Competitividad), del que es investigador principal el Prof. Dr. Dr. h. c. mult. Diego-Manuel Luzón Peña, Catedrático de Derecho Penal de la Universidad de Alcalá de Henares, así como también en los proyectos de investigación "Las garantías penales como límite y guía en la solución de problemas penales complejos: la necesidad de evitar atajos" (Referencia: DER2013-47511-R, Ministerio de Ciencia e Innovación) y "Principios y garantías penales: sectores de riesgo" (Referencia: DER2016-76715-R, Ministerio de Ciencia e Innovación) de los que es investigador principal el Prof. Dr. Dres. h. c. Miguel Díaz y García Conlledo, Catedrático de Derecho Penal de la Universidad de León, y de cuyos equipos de trabajo forma parte. 


\section{Abstract}

In this paper the different concepts of action, omission and commission by omission are studied. It is analysed whether this distinction is important or not, and the regulation contained in the Spanish Criminal Code is explained. Finally, these issues are studied through the analysis of different cases.

\section{Keywords}

Action, omission, Spanish Criminal Code, cases.

\section{Sumario}

1. Consideraciones previas. 2. Los conceptos de acción y omisión. 3. Las distintas clases de omisión. 4. La comisión por omisión: la teoría de la posición de garante y la teoría del incremento del riesgo. 5. La participación en comisión por omisión. 6. Regulación legal de la comisión por omisión: el art. 11 CP. 7. La distinción entre omisión, acción e infracción del deber de cuidado. 8. Análisis de las conductas de los profesionales sanitarios. 8.1. Concepto "reducido" de la conducta médico-sanitaria: la estratificación de la conducta médico sanitaria. 8.2. La delimitación entre acción y omisión a partir de la "contemplación global" de la intervención sanitaria. 9. Conclusiones. Bibliografía.

\section{Consideraciones previas}

La necesidad de estudiar, aunque no pueda ser aquí pormenorizadamente, las opiniones doctrinales relativas a la calificación de una conducta como activa u omisiva y en su caso de comisión por omisión, para después analizar, conforme a la postura adoptada, las conductas en el ámbito médico-sanitario, y más en concreto en los supuestos de intervención conjunta de varios profesionales, trae su causa en la complejidad que presentan muchos casos relativos a la división del trabajo cuando se trata de determinar el carácter (activo u omisivo) de la conducta de los profesionales sanitarios y, en especial, de las dificultades que entraña esta calificación en relación con la conducta de quien confía. Las dudas sobre cómo calificar determinadas conductas aparecen reflejadas en numerosos supuestos reales y en no pocas sentencias judiciales. A modo de ejemplo se pueden citar los casos, relativamente frecuentes, de intervenciones quirúrgicas en las que el anestesista abandona el quirófano con la anuencia del cirujano. Mientras el TS² resuelve estos casos decantándose por calificar la conducta del cirujano que confía indebidamente en el anestesista como omisiva, la mayoría de los autores se inclinan 
por afirmar el carácter activo de dicha conducta. Esta disparidad de criterios se puede ver en relación con la STS 4-9-1991 (RJ 1991/6021)3. En este caso el TS se refiere a la conducta del cirujano diciendo que "el procesado (...) debió percibir el peligro que el acto médico y las negativas condiciones implicaban para la vida del paciente. La conducta imprudente del recurrente comienza por no controlar la conexión del monitor al inicio de la operación y en su tolerancia o consentimiento a que el anestesista abandonase el quirófano. No podía desconocer por su condición de experto cirujano los riesgos que se producen en las intervenciones quirúrgicas efectuadas con anestesia general (...). No se trata de reprochar culpabilísticamente al recurrente por una conducta ajena, como se arguye en el motivo, sino por una conducta propia, de carácter omisivo, que es determinante de la ejecución de un resultado típico del correspondiente delito, o sea, como causación de un mal cierto y positivo, como ha recogido la doctrina de esta Sala desde la añeja sentencia de 23 de junio de 1933, relativa a la omisión en los delitos culposos. Una operación quirúrgica destinada a restablecer la salud o su mejoramiento, no está constituida por actividades inconexas de los sujetos que intervienen en ella, debiendo actuar todos ellos, anestesista, instrumentista y auxiliar, como los de este supuesto, cada uno en su cometido y para ayudar y facilitar la intervención que realiza el cirujano, pues ninguna de las demás actividades es autónoma en sí misma. El cirujano, a quien corresponde una específica actividad sobre el paciente, conoce y tiene el deber de conocer los riesgos de las operaciones con anestesia general. Si tolera que no se conecte el aparato monitor y no lo conecta él y además permite la ausencia del anestesista, consiente en su actuación quirúrgica un estado de riesgo determinante en adecuada relación causal con el resultado final del fallecimiento del paciente"4. Frente a esta calificación, algunos autores suelen referirse a la conducta del cirujano como una conducta activa imprudente ${ }^{5}$, otros en cambio sostienen que se trata

3 Sentencia del Tribunal Supremo, en adelante, STS; Repertorio de Jurisprudencia. Sentencias y Autos del Tribunal Supremo (base de datos online de Aranzadi westlaw.es), en adelante RJ

$4 \quad$ Es necesario observar que en ésta (y otras resoluciones judiciales) el juzgador se refiere a la relación de causalidad entre la conducta de un sujeto y el resultado a pesar de estar valorando una omisión. Pues bien, conviene recordar, en palabras de Luzón Peña, Diego-Manuel, Curso de Derecho Penal. Parte General, Universitas, Madrid, 1996, pp. 360 ss.; el mismo, Lecciones de Derecho Penal. Parte General, 3. ${ }^{\text {a }}$ ed., Valencia, Tirant lo Blanch, 2015, nm. 15/3, que "la causalidad o nexo causal es una relación lógico-real, normalmente de carácter material o físico, pero a veces de carácter psíquico (influyendo psíquicamente en otra persona), que se puede establecer entre una acción humana y un resultado. (...) En los delitos de omisión impropia -de comisión por omisión, que producen un tipo de resultado mediante omisión-, (...) no hay relación de causalidad material, pero sí se exige precisamente imputación objetiva del resultado".

5 Vid., entre otros, Jorge Barrelro, Agustín, La imprudencia punible en la actividad médico-quirúrgica, 
de una conducta omisiva, por lo que el cirujano podría responder del resultado en comisión por omisión ${ }^{6}$.

También surgen dudas en supuestos de delegación de funciones entre profesionales sanitarios. Un ejemplo sobre la dificultad para determinar si la conducta del que confía es activa u omisiva se encuentra en la STS 31-5-1982 (RJ 1982/2738) que condena al médico como autor de una falta con resultado de muerte cometida por imprudencia simple afirmando que "confió ciegamente, y de modo excesivo, en los miembros de ATS ${ }^{7}$ que debían observar y vigilar al traumatizado, sin tener en cuenta que la formación científica de dichos auxiliares, con ser estimable, no permite descargar sobre ellos toda la responsabilidad técnica de un caso de suma gravedad como lo era el de autos, y finalmente, permaneció más de 16 horas (...) desentendiéndose del caso, sin examinar personalmente, ni de otro modo, al internado, ni conocer ni comprobar las observaciones de sus subordinados, a requerimiento de uno de los cuales, al fin, acudió a la cabecera del referido internado cuando su estado ya presentaba síntomas muy alarmantes de focalidad y de inconsciencia y una tal gravedad que hizo inútil la intervención quirúrgica posterior que no evitó ya ni el coma profundo, nila descerebración, ni el fallecimiento del infeliz paciente, fallecimiento que forzosamente se ha de achacar a la fractura y fisura que padecía y que no fueron detectadas tempestivamente, y a la tardanza en el diagnóstico certero y en la intervención quirúrgica referida". El TS no deja claro si la conducta del médico a la que se le imputa el resultado de muerte tiene un carácter activo u omisivo. Se puede interpretar que la responsabilidad del superior trae su causa en el acto mismo de delegación en el inferior de una tarea para la que éste no estaba preparado, en cuyo caso parece que se está calificando como imprudente una conducta activa. Pero se puede pensar que la conducta que origina la responsabilidad del médico es la omisión del seguimiento de la actividad del subordinado, estando obligado por las circunstancias concretas del caso a acudir él personalmente a la sala donde se encontraba el paciente y a supervisar la corrección de las observaciones del ATS. Como se puede intuir, la calificación de la conducta de quien confía como activa u omisiva presenta ciertos problemas de difícil solución. Pero también es necesario referirnos a la conducta del tercero y determinar si se trata de una acción u omisión. En los ejemplos antepuestos, analizar la conducta del anestesista que se ausenta del quirófano, una vez que ha iniciado el proceso anestésico y, en el segundo supuesto, dilucidar si la conducta del ATS al cuidado del paciente es activa u omisiva. En estos

Madrid, Tecnos, 1990, pp. 139 s.; Gómez Rivero, Carmen, La responsabilidad penal del médico, Valencia, Tirant lo Blanch, 2003, pp. 425 s.

6 Vid., entre otros, Gimbernat Ordelg, Enrilue, "Causalidad, omisión e imprudencia", en ADPCP 1994, p. 23.

7 Ayudante Técnico Sanitario, en adelante ATS. 
casos se reproducirán los problemas comunes con los que nos enfrentamos a la hora de analizar este aspecto de la conducta, quizá incrementados por las peculiaridades y complejidades que presenta una actividad como la médico-sanitaria ${ }^{\text {. }}$

En resumen, los supuestos problemáticos que serán tratados aquí se reconducen a tres. En primer lugar, determinar cómo se puede calificar (activa u omisiva) la conducta del profesional sanitario, individualmente considerada, es decir, sin ponerla en relación con el resto de intervinientes. En segundo lugar, se trata de valorar como activa u omisiva, y en este caso afirmar o no la comisión por omisión, la conducta del profesional sanitario que confía inadecuadamente en un colega que realiza una determinada actuación sobre el mismo paciente. En tercer lugar, hay que valorar si el incumplimiento de los deberes de vigilancia o control que pesan sobre determinados profesionales, algunas veces en relación con actividades puntuales realizadas sobre un concreto paciente por otro profesional y otras respecto al desempeño general de sus funciones de una determinada persona o de un servicio o sección hospitalaria, puede constituir un caso de comisión por omisión a la que imputar el resultado lesivo que se produce sobre uno o varios pacientes.

Para ello seguiré el siguiente esquema: realizaré una exposición y valoración crítica de las principales posturas doctrinales acerca las cuestiones relativas a la acción, a la omisión y a la comisión por omisión. Comenzaré por una breve aclaración conceptual respecto al término "acción" y sus posibles usos en la dogmática penal. A continuación valoraré en qué medida se puede hablar de acción y omisión y qué significado, si es que tiene alguno relevante, posee tal distinción. Esta discusión tiene mucho que ver (y de ahí que pueda haber cierta repetición de argumentos) con la cuestión que se trata después: la comisión por omisión. Expondré las principales corrientes doctrinales que han desarrollado un concepto propio de comisión por omisión, así como la regulación contemplada en el CP9 actual, antes de adoptar una posición al respecto. Sentadas estas bases, trataré de responder a las dudas suscitadas anteriormente sobre la calificación, como acción u omisión, de determinadas conductas en el ámbito sanitario.

\section{Los conceptos de acción y omisión}

Las diferentes opiniones sobre la distinción entre omisión y acción, partiendo de un concepto normativo ${ }^{10}$, pueden ser ordenadas en dos grandes grupos. Por una parte,

8 Vid. Silva Sánchez, Jesús María, "Aspectos de la responsabilidad penal por imprudencia del médico anestesista. La perspectiva del Tribunal Supremo", en DS 2-1994, pp. 58 ss.

9 Código Penal, en adelante CP.

10 La mayoría de la doctrina adopta un criterio normativo (como criterio único o junto con un criterio ontológico) para abordar la distinción entre acción y omisión, como se puede ver en Octavio DE Toledo 
aquellos que consideran que existe una diferencia material, de contenido, entre una y otra forma de conducta ${ }^{11}$. Por otra parte, aquellos que entienden que tal diferencia es sólo formal, hasta considerar que todo tipo penal formulado en un sentido positivo (omisión) ${ }^{12}$ puede ser reformulado en un sentido negativo (acción) ${ }^{13}$ y viceversa, de manera que se concluye que lo positivo y lo negativo está presente en todos los tipos penales ${ }^{14}$. Entienden que la distinción entre acción y omisión no responde a aspectos sustancialmente diferentes de la conducta realizada.

Si este razonamiento se detuviese aquí no habría mayor problema, sin embargo no es así. Para los primeros, la diferencia material entre una conducta activa y una conducta omisiva significa que el desvalor de injusto (o de conducta) que se genera con una u otra forma de actuación es distinto, considerando que la conducta omisiva es menos desvalorada, en principio, que la activa. Esto tiene consecuencias importantes en la concepción de la comisión por omisión. Para que a una omisión se le pueda imputar un resultado lesivo igualándola en pena a la conducta activa generadora de ese mismo resultado, se exigirá que se cumplan una serie de requisitos más estrictos; de alguna manera, se exige, un "plus"15 en el desvalor de acción. Éste es el punto de partida de la

y Ubieto, Emilio/Huerta Tocildo, Susana, Derecho penal. Parte General: Teoría jurídica del delito, 2. ${ }^{\text {a }}$ ed., Madrid, Castellanos, 1986, p. 559; Huerta Tocildo, Susana, Problemas fundamentales de los delitos de omisión, Madrid, Ministerio de Justicia e Interior, Centro de Publicaciones, 1987, pp. 307 s.; Gimbernat Ordeig, Enrioue, "Sobre los conceptos de omisión y de comportamiento", en ADPCP 1987, p. 583; Paredes Castañón, José Manuel, El riesgo permitido en Derecho penal (Régimen jurídico-penal de las actividades peligrosas), Madrid, Ministerio de Justicia e Interior, Centro de Publicaciones, 1995, pp. 204 s.; Luzón Peña, Diego-Manuel, Curso de Derecho Penal. Parte General, cit., p. 249; el mismo, Lecciones de Derecho Penal. Parte General, cit., nm. 10/5; Silva Sánchez, Jesús María, "Omisión", en Luzón Peña, Diego-Manuel (dir.), EPB, Granada, Comares, 2002, p. 962; Maqueda Abreu, María Luisa/ Marín De Espinosa Ceballos, Elena, en Zugaldía Espinar, José Miguel/Pérez Alonso, Esteban Juan, Derecho penal. Parte General, 2. a ed.,Valencia, Tirant lo Blanch, 2004, p. 796; Mir Puig, Santiago, Derecho Penal. Parte General, 10. ${ }^{a}$ ed., Barcelona, Reppertor, 2015, p. 309; Dopico Gómez-AlleR, Jacobo, Omisión e injerencia en Derecho penal, Valencia, Tirant lo Blanch, 2006, p. 674; Muñoz Conde, Francisco/García Arán, Mercedes, Derecho Penal. Parte General, 9. ${ }^{a}$ ed., Valencia, Tirant lo Blanch, 2015, p. 238.

11 Sobre los primeros pasos de esta distinción en la doctrina alemana vid. Dopico Gómez-Aller, Jacobo, Omisión e injerencia en Derecho penal, cit., pp. 148 ss. Expone aquí las "teorías del deber jurídico material o de la antijuridicidad material", que buscan por primera vez la diferencia entre acción y omisión en términos normativos.

12 A modo de ejemplo, art. $195 \mathrm{CP}$ (socorre), art. $450 \mathrm{CP}$ (impide, informa).

13 A modo de ejemplo, art. $138 \mathrm{CP}$ (no mates), art. $147 \mathrm{CP}$ (no lesiones).

14 Sobre las razones que llevan al legislador a formular un tipo como una norma de prohibición o de mandato se puede ver Paredes Castañón, José Manuel, El riesgo permitido en Derecho penal (Régimen jurídico-penal de las actividades peligrosas), cit., pp. $250 \mathrm{~s}$.

15 Este es el término empleado por Octavio De Toledo y Ubieto, Emilio/Huerta Tocildo, Susana, Derecho penal. Parte General: Teoría jurídica del delito, cit., p. 573. 
teoría de la posición de garante. Por su parte, aquella postura que considera que entre acción y omisión no hay una diferencia sustancial y se reduce a una diferencia formal o si se quiere, por qué no, "nominal", esta distinción no tendrá relevancia", al menos no se le otorgarán las consecuencias jurídicas que se plantean desde la primera postura. Desde este planteamiento la comisión por omisión requiere que entre la omisión y la acción exista, ni más ni menos, una identidad estructural y material.

En mi opinión, la distinción entre omisión y acción es de carácter normativo, ya que ontológicamente lo que existen son comportamientos o conductas (acciones en sentido amplio $)^{17 / 18}$. El carácter activo u omisivo vendrá dado por la comparación de la

16 No obstante, desde esta postura se admite que en el fondo existen diferencias, no identificadas, entre una y otra forma de conducta. Así Paredes Castañón, José Manuel, El riesgo permitido en Derecho penal (Régimen jurídico-penal de las actividades peligrosas), cit., p. 248.

17 Respecto al concepto de acción como presupuesto del delito han existido y existen distintas teorías que tratan de definirlo partiendo en unos casos de un concepto ontológico y en otros de un concepto normativo. Además de las principales teorías de la acción como son la concepción causal (reformulada por el concepto personal de acción -que es el que aquí se defiende-), final y social, que cuentan con una mayor tradición y con más seguidores, existen otras como la sostenida en la doctrina española por Bacigalupo Zapater, Enrioue, Principios de Derecho Penal. Parte General, 5. ${ }^{a}$ ed., Madrid, Akal, 1998, pp. 390 ss., quien entiende la acción como comportamiento exterior evitable, al afirmar que "la acción, (...), es todo comportamiento exterior evitable, es decir, un comportamiento que el autor hubiera podido evitar si hubiera tenido un motivo para hacerlo. Ejemplo: el autor que dispara sobre su víctima y le produce la muerte hubiera podido evitar esa acción si hubiera querido; el que como consecuencia de una fuerza irresistible (por ejemplo, una avalancha de personas) que lo empuja contra otra persona le causa lesiones, no hubiera podido evitar lesionar a otro. En el primer caso existe una acción; en el segundo no. Sólo una conducta evitable puede ser expresiva del sentido social que interesa al Derecho penal. La evitabilidad no tiene que ser conocida por el agente pero sí debe referirse a sus concretas capacidades de acción. Por tales razones no parecen acertadas las críticas que el criterio de la evitabilidad ha merecido de parte de la doctrina española, en la que se confunde la evitabilidad con la motivación del sujeto (...). Este concepto de acción tiene la función principal de eliminar del ámbito del Derecho penal todo hecho totalmente irrelevante"; Zugatdía Espinar, José Miguel, en Zugaldía Espinar, José Miguel/Pérez Alonso, Esteban Juan, Derecho penal. Parte General, 2. ${ }^{a}$ ed.,Valencia, Tirant lo Blanch, 2004, p. 423, opta por un concepto híbrido, al entender que "la acción es 'un comportamiento humano exterior evitable"'; Octavio De Toledo y Ubieto, Emilio/ Huerta Tocildo, Susana, Derecho penal. Parte General: Teoría jurídica del delito, cit., p. 41, consideran que ninguna de las principales teorías es capaz de proporcionar un concepto de acción común a todas las formas de aparición del delito, debido a la diversidad que éstas presentan. Así señalan que "si, conforme creemos, no es posible alcanzar un concepto unitario -ontológico o no- de acción, deben abandonarse los intentos de conseguirlo y sustituirse el no logrado concepto unitario de acción por el acogimiento de un concepto normativo de conducta típica". Es decir, se examina directamente la acción jurídicopenalmente relevante en cuanto acción típica, excluyendo del concepto cualquier otra que no cumpla los requisitos típicos, abandonando, por tanto, la idea de la acción como elemento base del resto de los elementos del tipo y autónomo respecto de éste.

18 Hay que poner de manifiesto que la concepción ontológica de la "acción" (en cuanto presupuesto del tipo) es la que más se ajusta a la distinción que acabamos de realizar. En mi opinión, de todas las teorías existentes, la que se refiere a un "concepto personal de acción" inspirada claramente en 
concreta conducta realizada con la norma penal, formulada en un sentido positivo 0 negativo. Es decir, es sólo tras haber pasado el "filtro" jurídico cuando se puede concluir si estamos ante una acción o una omisión ${ }^{19}$. A partir de esta premisa, la conducta será

la teoría causal de acción es la correcta. Luzón Peña, Diego-Manuel, Curso de Derecho Penal. Parte General, cit., p. 272; el mismo, Lecciones de Derecho Penal. Parte General, cit., nm. 10/43, 30/4, aunque este autor introduce ciertos matices, fundamentalmente la presencia de la voluntad, que diferencian parcialmente su concepción de la originaria tesis del concepto personal de acción. En la doctrina española Gimbernat Ordeig, EnRioue, "Sobre los conceptos de omisión y de comportamiento", cit., p. 587, defiende el concepto personal de acción en su versión original, en el que se prescinde de la voluntad o del comportamiento "querido". Para este autor el comportamiento "podría definirse ya como relación del Yo consciente y físicamente libre con el mundo exterior manejando procesos causales (esto es: incidiendo en o alterando los procesos causales o dejando que éstos sigan su curso o que no se inicien)". Por todos, Roxin, Claus, Allgemeiner Teil, t. I: Grundlagen. Der Aufbau der Verbrechenslehre, 3. ${ }^{a}$ ed., München, Beck, 1997 (Derecho penal, Parte General, t.l: Fundamentos. La estructura de la teoría del delito, Madrid, Civitas, 1997), § 842 (todas las citas que realizo de esta obra se toman de la traducción. Cuando interese destacar alguna cuestión del original, se indicará expresamente), sostiene que "un concepto de acción ajustado a su función se produce si se entiende la acción como 'manifestación de la personalidad', lo que significa lo siguiente: En primer lugar es acción todo lo que se puede atribuir a un ser humano como centro anímico-espiritual de acción, y eso falta en caso de efectos que parten únicamente de la esfera corporal ('somática') del hombre, o 'del ámbito material, vital y animal del ser', sin estar sometidos al control del 'yo', de la instancia conductora anímico-espiritual del ser humano. Si un sujeto es empujado con fuerza irresistible contra la luna de una ventana, 0 si durante el sueño, 0 en un delirio 0 en un ataque convulsivo, el mismo golpea en torno suyo, o si reacciona de modo puramente reflejo, todas éstas son manifestaciones que no son dominadas o dominables por la voluntad y la conciencia y por tanto no pueden ser calificadas como manifestaciones de la personalidad, ni imputadas a la capa anímico-espiritual de la 'persona'. Por otra parte, es evidente que los pensamientos y los impulsos de la voluntad pertenecen a la esfera espiritual-anímica de la persona, pero en tanto permanecen encerrados en lo interno y no se ponen en relación con los sucesos del mundo exterior, no son manifestaciones de la personalidad y por tanto no son acciones".

19 La "acción" entendida como un concepto prejurídico tanto desde concepciones ontologicistas como mixtas y normativas. Así, entre estas últimas, Muñoz Conde, Francisco/García Arán, Mercedes, Derecho Penal. Parte General, cit., p. 217, señalan que "esto [scil. teoría del concepto significativo de acción] no quiere decir que haya que renunciar a un concepto prejurídico de acción sino simplemente que el mismo no puede reducirse a simples procesos ontológicos, causales o finales, desconectados de cualquier tipo de valoraciones"; Mır Puig, Santiago, Derecho Penal. Parte General, cit., pp. 188 s., considera que "el concepto de 'acción' o 'comportamiento' que importa al Derecho penal no puede obtenerse de la sola contemplación de la realidad de los hechos humanos - de su 'estructura lógico-objetiva' en el sentido de Welzel-, sino que depende también de las exigencias del Derecho penal. Sin duda, los comportamientos relevantes para el Derecho penal existen antes de éste y con independencia de sus condicionamientos: el matar existiría aunque no se hallara penado por ley. Mas también existen otros hechos que no pueden importar al Derecho penal ni ser incluidos en los conceptos de 'acción' o 'comportamiento' que aquí interesan. La selección de los hechos jurídicopenalmente relevantes sólo puede efectuarse desde el prisma del Derecho penal (...). Se trata de una selección entre distintos sentidos posibles de comportamientos preexistentes al Derecho penal. No todo lo que puede considerarse como comportamiento al margen del Derecho penal debe reputarse tal para éste, pero tampoco cabría convertir en comportamiento para el Derecho penal algo que 
activa (acción) si infringe una norma prohibitiva, mientras que será omisiva (omisión) si infringe una norma de mandato. En determinados casos y en función de los tipos penales a los que se refieran las conductas concretamente realizadas, "descubrir" cuándo nos encontramos ante un comportamiento activo u omisivo es relativamente sencillo. Pensemos algún ejemplo respecto al delito de omisión del deber de socorro (art. $195 \mathrm{CP}^{20}$ ). Así, si el sujeto que observa cómo el herido tras caer de su bicicleta en un camino de montaña se desangra, sin que ninguna persona se encuentre ayudándole y no acude en su auxilio ni sale en busca de ayuda estará realizando una conducta de corte omisivo encajable en el supuesto del art. 195 CP. Pero en otras ocasiones tal distinción no es tan fácil. En este sentido Muñoz Conde/García Arán ponen de manifiesto que consistiendo todo delito en una infracción del deber y siendo éste el punto neurálgico de la omisión, en principio el elemento distintivo respecto a la acción, se hace difícil determinar, en ciertos casos, cuándo la conducta puede ser calificada como activa u omisiva, ya que "el mismo proceso causal puede ser valorado, por tanto, desde el punto de vista de una norma prohibitiva o desde el punto de vista de una norma imperativa, lo que importa es saber en cada caso cuál es la parte de ese proceso causal que interesa penalmente hablando"21. Esta idea de la dificultad de dar con la calificación de la conducta en determinados supuestos es expresada por otros autores; MIR Puıg señala que "del concepto de omisión que se empezó por proponer se deduce que la diferencia entre los delitos de acción y de omisión se halla en la naturaleza de la norma, prohibitiva o preceptiva respectivamente. Pero a veces sucede que una misma conducta parece infringir a la vez ambas clases de normas. Debe entonces decidirse si nos hallamos frente a un delito de acción o de omisión (aparte de la posibilidad de que se produzca un concurso de delitos de acción y de omisión)"22.

previamente no pudiera ser calificado de tal en ningún sentido posible. (...) Por otra parte, lo dicho significa que mantener un concepto jurídico-penal de acción no supone negar que puedan utilizarse otros sentidos más amplios de acción a efectos distintos de la teoría del delito. (...) Significa sólo que, a los efectos de la teoría del delito se elige un determinado sentido posible del concepto de acción, sin negar la existencia de otros sentidos posibles, útiles a otros efectos". Por su parte, cfr. Luzón Peña, Diego-Manuel, Curso de Derecho Penal. Parte General, cit., p. 269; el mismo, Lecciones de Derecho Penal. Parte General, cit., nm. 10/5, 30/7 ss.

20 Art. 195 CP: "1. El que no socorriere a una persona que se halle desamparada y en peligro manifiesto y grave, cuando pudiere hacerlo sin riesgo propio ni de terceros, será castigado con la pena de multa de tres a doce meses. 2. En las mismas penas incurrirá el que, impedido de prestar socorro, no demande con urgencia auxilio ajeno. 3. Si la víctima lo fuere por accidente ocasionado fortuitamente por el que omitió el auxilio, la pena será de prisión de seis meses a 18 meses, y si el accidente se debiere a imprudencia, la de prisión de seis a cuatro años".

21 Muñoz Conde, Francisco/García Arán, Mercedes, Derecho Penal. Parte General, cit., p. 239.

22 Mir Puig, Santiago, Derecho Penal. Parte General, cit., p. 310. 
Para solucionar estos problemas se han desarrollado distintos criterios y teorías. En todo caso, lo que interesa destacar aquí es que la intercambiabilidad de omisión y acción, cuando de imputar un resultado a la conducta del individuo se trata, hace que esta distinción tenga menos trascendencia de la que en un principio pudiera aparentar. Lo realmente importante es si el resultado lesivo se puede imputar (objetivamente) a la conducta de un individuo y si dicha conducta ha infringido o no el deber de cuidado.

\section{Las distintas clases de omisión}

La dogmática penal ha realizado diferentes clasificaciones de las omisiones. Así, se ha distinguido entre omisiones propias e impropias, omisiones puras y comisión por omisión e incluso algunos autores superan esta diferenciación bipartita para plantear la existencia de tres formas de omisión, concretamente omisión pura, delitos de omisión y resultado, y delitos de comisión por omisión.

Por una parte, la distinción entre omisiones propias e impropias se utiliza para diferenciar a las omisiones expresamente tipificadas en el CP de aquellas otras que no se encuentran tipificadas ${ }^{23}$. Sin embargo, otros autores prescinden de lo anterior y se inclinan por utilizar, bajo la misma nomenclatura, otro criterio diferenciador, que se concreta en la exigencia o no de la producción de un resultado. Según esta última postura, en aquellos casos en los que se castiga el hecho de no realizar la conducta debida, independientemente de que se produzca o no un resultado de lesión o de peligro para un bien jurídico, estaríamos ante delitos de omisión propia. Ejemplo paradigmático de esta clase de omisiones es el contemplado en el art. 195.1 y 2 CP24 (omisión del deber de socorro). Por su parte, cuando se requiere la imputación de un resultado a la omisión realizada para poder castigar esa conducta, entonces se la

23 Sobre esta diferenciación señala Gimbernat Ordeig, EnRIQue, "La omisión impropia en la dogmática penal alemana. Una exposición", en ADPCP 1997, p. 10, sin compartirla, lo siguiente: "Según otra dirección, los auténticos delitos impropios de omisión serían aquellos en los que la reconducción del resultado a la inactividad no está expresamente tipificada (el CP, por ejemplo, no recoge explícitamente que la madre que no liga el cordón umbilical responde de la muerte de su hijo), mientras que no serían delitos impropios de omisión -sino propios- aquéllos en los que el legislador tipifica expresamente una conducta inactiva, tanto si no la pone en relación con un resultado (ejs.: arts. 196 y 450 CP) como si reconduce el resultado a una inactividad, poniendo en conexión, por consiguiente, una inactividad con un resultado (así, p. ej.: en el art. 432, el CP imputa directamente el perjuicio patrimonial de la sustracción de los fondos públicos al funcionario que consiente, esto es, no impide, que otros los sustraigan; en el art. 176, se hace responsable de las torturas causadas a la autoridad o funcionario que permite, esto es y entre otros comportamientos: que no evita, que otras personas las causen)".

24 Art. 195 CP: "1. El que no socorriere a una persona que se halle desamparada y en peligro manifiesto y grave, cuando pudiera hacerlo sin riesgo propio ni de terceros, será castigado con la pena de multa de tres a doce meses. 2. En las mismas penas incurrirá el que, impedido de prestar socorro, no demanda con urgencia auxilio ajeno". 
identifica con una omisión impropia, que puede estar tipificada expresamente, como sucede en el art. 176 CP25, pero que en la mayoría de los casos no encontrará una tipificación expresa, sino que deberán ser "deducidas" a partir de los "tipos comisivos". Esta forma de entender la clasificación en omisiones propias e impropias es acogida, entre otros autores, por GimBernat Ordeig ${ }^{26}$, Bacigalupo ${ }^{27}$, Luzón Peña ${ }^{28}$.

Algunos autores prefieren mantener una distinción bipartita, como la sostenida por quienes diferencian entre omisiones propias e impropias pero utilizando los términos omisión pura y comisión por omisión. La omisión pura es aquella que tiene lugar cuando el sujeto incumple un deber de actuar, sancionándose independientemente del resultado acaecido, es decir, se produzca o no un resultado y, de producirse éste, cualquiera que sea su gravedad. Los delitos de comisión por omisión guardan paralelismo con los delitos comisivos de resultado, ya que al igual que en estos últimos, se exige la producción de un resultado y su imputación a la omisión realizada ${ }^{29}$.

25 Art. 176 CP: “Se impondrán las penas respectivamente establecidas en los artículos precedentes a la autoridad o funcionario que, faltando a los deberes de su cargo, permitiere que otras personas ejecuten los hechos previstos en ellos". A través de este artículo se castiga al sujeto que omitiendo la acción a la que está obligado por su cargo permite que sus subordinados torturen a una persona (art. 174.1 CP) 0 atenten contra la integridad moral de una persona (art. $175 \mathrm{CP}$ ).

26 Gimbernat Ordeig, Enrioue, en Cobo Del Rosal, Manuel (dir.), Comentarios al Código penal, Madrid, Edersa, t. I, 1999: arts. 1-18, pp. 412 s., indica que "mientras que en el primer supuesto [omisión impropia] esa omisión recibe el mismo tratamiento que una acción causante del resultado, en el segundo el sujeto responde únicamente por la omisión como tal omisión [omisión propia] sin que se pueda reconducir a ésta el eventual resultado de la muerte del infartado (...). Con la expresión omisión propia se quiere poner de relieve que aquí sí que estamos ante inactividades en sentido estricto que no pueden ser puestas en conexión, por tanto, con lesión alguna. En consecuencia, el art. 195 se consuma con el no auxilio al desamparado, siendo irrelevante para la aplicación de dicho tipo penal porque la lesión nunca se le puede imputar al omitente- que el desamparado posteriormente muera o consiga sobrevivir porque, por ejemplo, las lesiones no eran letales o porque, aun siendo muy graves, otras personas le prestaron auxilio a tiempo"; el mismo, "La omisión impropia en la dogmática penal alemana. Una exposición", cit., p. 10

27 Bacigalupo Zapater, Enrique, Principios de Derecho Penal. Parte General, cit., pp. 392 s., afirma que "los delitos impropios de omisión son aquéllos en los que el mandato de acción requiere evitar un resultado que pertenece a un delito de comisión y son, por lo tanto, equivalentes a los delitos de comisión. Los delitos propios de omisión, sólo requieren la realización de una acción, y su punibilidad no depende de la existencia de un delito activo".

28 Luzón Peña, Diego-Manuel, “Omisión de socorro: distinción entre omisión propia e impropia (Comentario a la STS 3-3-1980)", en RDCir 1980, pp. 386 ss.; el mismo, Curso de Derecho Penal. Parte General, cit., p. 306; el mismo, Lecciones de Derecho Penal. Parte General, cit., nm. 30/16 ss.; explica el significado de cada uno de los términos y recoge su equivalencia a las expresiones "omisión pura" y "comisión por omisión".

29 Sobre esta distinción terminológica, cfr. Luzón Peña, Diego-Manuel, “Omisión de socorro: distinción entre omisión propia e impropia (Comentario a la STS 3-3-1980)", cit., p. 387; el mismo, Curso de 
Materialmente, esta clasificación no difiere de la realizada por quienes distinguen entre omisión propia e impropia en función de que concurra o no un resultado imputable a la acción, sin embargo, se prefiere la nomenclatura omisión pura y comisión por omisión por considerar que es la mejor forma de evitar las confusiones que se derivan de la polisemia adquirida a lo largo del tiempo por los términos "propia" e "impropia". Así lo entienden Mir PuIG ${ }^{30}$, Corcor BIDASOL2031. Sin adoptar una clasificación bipartita, Silva SÁnchez también muestra sus preferencias por esta nomenclatura por razones de tradición en el uso y mayor expresividad ${ }^{32}$.

Otros autores consideran insuficiente esta distinción bipartita de las omisiones, por entender que no abarcan todas las posibles clases que se pueden presentar. Así, se ha desarrollado una distinción tripartita que tiene una amplia acogida en la doctrina.

Derecho Penal. Parte General, cit., pp. 306 s.; el mismo, Lecciones de Derecho Penal. Parte General, cit., nm. 30/16 ss.

30 Mir Puig, Santiago, Derecho Penal. Parte General, cit., p. 312, quien opta por distinguir entre omisión pura y comisión por omisión señalando que "de la misma forma que los tipos de acción se dividen en tipos de mera actividad y de resultado, los de omisión pueden contentarse con el solo no hacer algo determinado, o requerir además la no evitación de un resultado. Los primeros, contrapartida de los delitos de mera actividad en la omisión, constituyen tipos de omisión pura, en tanto que los segundos, equivalente a los delitos de resultado, reciben el nombre de comisión por omisión". A continuación este autor explica por qué elige la terminología "omisión pura" y "comisión por omisión" en lugar de la tradicional "propia" e "impropia". "Esta terminología es preferible a la de delitos de omisión propia e impropia, pues, aunque un importante sector doctrinal la considera equivalente, otra dirección reserva el nombre de omisión impropia para los casos que no se hallan expresamente previstos en la ley, incluyendo en la omisión propia las figuras legales, sean de pura omisión, sean de comisión por omisión". En este sentido también se expresa Silva Sánchez, Jesús María, "Omisión", cit., p. 963, advirtiendo que "según otra clasificación menos frecuente en nuestro país, a los delitos de omisión pura se les denomina también delitos de omisión propia y a los de comisión por omisión, delitos de omisión impropia. Sin embargo, ambas clasificaciones no son siempre superponibles, en la medida en que esta última se usa también frecuentemente en el sentido de que son omisiones propias las tipificadas expresamente por la ley, mientras que son omisiones impropias las que carecen de previsión legal expresa".

31 Vid. Corcoy Bidasolo, Mirentxu, El Delito imprudente. Criterios de imputación del resultado, Barcelona, PPU, 1989, p. 67.

32 Silva Sánchez, Jesús María, El delito de omisión. Concepto y sistema, Barcelona, Bosch, 1986, pp. 318 s., señala que "todas las razones anteriores serían probablemente suficientes para rechazar también la clasificación española tradicional. De hecho, ésta, entendida como contraposición exclusiva de omisión pura y comisión por omisión, no es en absoluto de recibo. Sin embargo, existen razones para conservar, al menos, la terminología. En primer lugar, su carácter usual, arraigado en la doctrina y la jurisprudencia. Además, el carácter gráfico de la expresión 'comisión por omisión' que, pese a no acogerse en su tenor tradicional, todavía puede ser útil, en orden a expresar la realización por omisión de determinados tipos legales en los que la descripción típica positiva haría pensar en un precepto prohibitivo y en una realización comisiva". Este autor rechaza esta clasificación al considerarla insuficiente para reflejar las distintas clases de omisiones. 


\section{Entre otros, SILVA SÁnchez ${ }^{33}$ establece tres categorías en los delitos de omisión: delitos}

33 Silva Sánchez, Jesús María, El delito de omisión. Concepto y sistema, cit., pp. 343 ss., 347 s., distingue "dos grupos de omisiones puras: las omisiones puras generales, esto es, realizables por todos (quivis ex populo) los que pudiendo llevar a cabo la acción indicada no la llevan a término; y las omisiones puras de garante. La existencia de omisiones puras generales se debe a consideraciones de solidaridad general en aras de la protección de bienes jurídicos individuales. De ahí que su realización, en la que pueden incurrir, además, todos los ciudadanos que, estando en situación, no cumplen la acción indicada, sea, en idénticas circunstancias, menos grave que la de una omisión pura de garante, por ejemplo. (...) Todas las omisiones puras generales han de hallarse, además, expresamente tipificadas como tales en preceptos legales de descripción negativa. Frente a lo anterior, las omisiones puras de garante tienen su fundamento en la existencia de una base funcional específica. Ello determina que sólo puedan ser realizadas por un determinado círculo de sujetos caracterizados por la ostentación de una posición de responsabilidad especial. Por esa misma razón, se trata de omisiones de mayor gravedad, en idénticas circunstancias, que las generales. Pese a lo cual, como ya hemos indicado, consideraciones valorativas y estructurales determinan que no se equiparen a la creación activa de un riesgo de producción del resultado que no ha sido evitado. Se trata, pues, de omisiones de 'gravedad intermedia";; "(...) en el seno de estas últimas, por su parte, cabe distinguir entre aquellas que aparecen expresamente tipificadas como tales omisiones de gravedad intermedia y aquellas otras en que no se da dicha tipificación. Éstas, para las que se propugna de lege ferenda una regulación específica como cualificaciones de los tipos de omisión de socorro y de impedir determinados delitos, de lege lata aparecerán, en principio, como realizaciones típicas omisivas puras generales"; "las omisiones referidas a resultado se caracterizan todas ellas por la posibilidad de imputárseles un resultado trascendente a la no-realización de la conducta indicada y que, a consecuencia de este hecho, no ha sido evitado por el sujeto. También son elementos comunes a esta segunda gran categoría de realizaciones típicas omisivas el estar fundadas en la existencia de una base funcional específica, la concurrencia, en todo caso, de un círculo restringido de sujetos que son los únicos que pueden realizarlas y, por último, desde el punto de vista valorativo, el tratarse de hechos más graves, en similares circunstancias, que las contempladas en la clase de omisiones puras. Sin embargo, aquí terminan los puntos de contacto. la aparición de dos elementos de distinción: el de la identidad estructural (equivalencia) con la comisión y el de la tipificación expresa en preceptos de descripción negativa, obliga a proceder a una tripartición. Así, una primera categoría, ciertamente marginal, de omisiones referidas a resultado viene constituida por aquellas que, apareciendo expresamente tipificadas en preceptos de descripción negativa y siéndoles imputado un resultado, carecen sin embargo de una paralela realización comisiva de la que puedan considerarse equivalentes; son pues, omisiones referidas a resultado sin equivalencia comisiva (sin Begehungsgleichheit). Una segunda categoría acoge aquellas realizaciones típicas omisivas referidas a resultado que muestran equivalencia con la correspondiente comisión activa (con Begehungsgleichheit); es decir, a las que cabe imputar el resultado en idéntica medida que a la creación activa del riesgo de producción del mismo. Sin embargo, tampoco esta categoría es unitaria. La primera subcategoría dentro de ella la constituyen las omisiones penales que aparecen expresamente acogidas, en descripciones negativas, por preceptos legales que contemplan, a la vez, la correspondiente comisión activa. Son las omisiones referidas a resultado, con equivalencia comisiva, acogidas por los tipos legales en expresas descripciones negativas; brevemente 'omisiones con equivalencia comisiva legalmente determinadas'. Por fin, la segunda subcategoría se refiere a aquellas omisiones penales, referidas a resultado y equivalentes con la comisión, que no se contemplan en precepto legal alguno con una descripción típica negativa. Al contrario, la única posibilidad de demostrar su existencia como tales realizaciones típicas omisivas es fundamentar su inclusión en tipos legales de descripción positiva, tradiciones y, como veremos, incorrectamente calificados de 'tipos comisivos', 'causales' o 'prohibitivos'. Esta peculiar situación determina la aparición de específicos problemas de toda índole: normológicos, jurídico-constitucionales, axiológicos, dogmático-estructurales, etc. Para designarla, puede ser todavía útil, pese a su equivocidad y básica incorrección, la expresión 'comisión por omisión'"'; Silva Sánchez, Jesús María, "La responsabilidad penal del médico por omisión", en MiR Puig, Santiago (ed.), Avances de la Medicina y Derecho Penal, Barcelona, PPU, 1988, p. 135, simplificando 
de omisión pura, delitos de omisión y resultado, y delitos de comisión por omisión. Para llevar a cabo esta clasificación utilizan dos criterios. Por una parte el análisis de la exigencia de un resultado imputable al autor de la omisión y por otra, el análisis de la posición que ocupa el autor en relación con el bien jurídico protegido (es decir, si ocupa o no una posición de garante). Según estos criterios, delitos de omisión pura serán los asimilados a los delitos de mera actividad, la infracción penal se comete por el solo hecho de no realizar la acción debida. Los delitos de comisión por omisión son aquéllos en los que a la omisión se le imputa el resultado en los mismos términos en los que se le imputaría a una acción. La categoría intermedia es denominada delitos de "omisión y resultado"34, aunque también se identifica con las expresiones de "omisiones de gravedad intermedia"35, "omisiones puras agravadas"36, "omisiones de garante" ${ }^{137}$, "omisiones puras de garante"38. Se incluirían en esta subespecie aquellas omisiones en las que sobre el sujeto en cuestión recae un especial deber de protección del bien jurídico, un deber que trae su causa en una intervención anterior sobre ese bien o en una obligación legal o contractual. El autor de la omisión está obligado a actuar por especiales circunstancias que lo sitúan en lo que se conoce como posición de garante respecto a ese bien jurídico. Sin embargo, no se le imputa el resultado lesivo sufrido por el bien jurídico. Así pues, esta categoría constituiría una mezcla entre los delitos de omisión pura y los delitos de comisión por omisión. Un ejemplo sería el del art. 195.3 CP39, en el que se contempla una agravación de la pena respecto a la omisión

la exposición afirma: "Por un lado, existen 'omisiones puras generales', como la de socorro. Por el otro, 'omisiones puras de garante'. Éstas habrían de castigarse con una pena más o menos agravada por encima del marco del delito de omisión de socorro; pero son insuficientes para la equiparación con la comisión activa. (...) Por último, existen supuestos de 'comisión por omisión', equivalente, idénticos estructural y materialmente a la comisión activa. Estos requieren algo más que la mera posición de responsabilidad (garantía) y se castigarán, naturalmente, con las penas previstas en los tipos de la Parte especial".

34 Silva Sánchez, Jesús María, “Omisión”, cit., p. 963.

35 Silva Sánchez, Jesús María, "La responsabilidad penal del médico por omisión", cit., p. 135; el mismo, "Comisión' y 'omisión'. Criterios de distinción", en CuadDJ 1994-XXIII, p. 19; el mismo, "Omisión", cit., p. 963.

36 Silva Sánchez, Jesús María, “'Comisión' y 'omisión'. Criterios de distinción”, cit., p. 19.

37 Silva Sánchez, Jesús María, "Omisión", cit., p. 963.

38 Vid. Silva Sánchez, Jesús María, El delito de omisión. Concepto y sistema, cit., p. 344; el mismo, "La responsabilidad penal del médico por omisión”, cit., p. 135; el mismo, “'Comisión' y 'omisión'. Criterios de distinción", cit., p. 19; Maqueda Abreu, María Luisa/Marín De Espinosa Ceballos, Elena, en Zugaldía Espinar, José Miguel/Pérez Alonso, Esteban Juan, Derecho penal. Parte General, cit., p. 800.

39 Art. 195.3 CP: "Si la víctima lo fuere por accidente ocasionado fortuitamente por el que omitió el auxilio, la pena será de prisión de seis meses a 18 meses, y si el accidente se debiere a imprudencia, la de prisión de seis meses a cuatro años". 
pura de los apartados anteriores que se justifica, según esta postura, precisamente por la especial posición que ocupa el sujeto a pesar de que el resultado no se le pueda imputar. También contemplan una clasificación tripartita de la omisión MuÑoz ConDE/ GARCía ARán, compartiendo, parcialmente, la terminología anterior, pero sin acoger el significado que los autores mencionados otorgan al delito de "omisión y resultado"40. Realmente ésta es una posición reconducible a la que sostiene la distinción entre omisión propia e impropia.

De todas las denominaciones señaladas, considero que la más adecuada es la que realiza una distinción bipartita y utiliza para ello los términos "omisión pura" y "comisión por omisión", ya que en mi opinión es la más representativa de las diferentes modalidades bajo las que puede presentarse una conducta omisiva y, además, se evita la confusión de los términos "propia" e "impropia".

\section{La comisión por omisión: la teoría de la posición de garante y la teoría del incremento del riesgo}

Los supuestos de omisión pura no ofrecen "grandes" problemas. En estos casos, el tipo penal es formulado expresamente como una norma de mandato, que obliga a hacer algo determinado. El problema surge respecto a aquellos tipos penales que son redactados como normas de prohibición ${ }^{41}$. Puede ocurrir que la conducta realizada no infrinja la norma de prohibición expresada típicamente, de manera que no se podrá calificar como conducta activa, sin embargo puede infringir el reverso de esa norma prohibitiva, subyacente en el tipo, es decir, la norma de mandato. Calificándose la conducta como omisiva, la pregunta será ipuede igualarse esa conducta omisiva a la conducta activa que parece ser la primera que quiere evitar y castigar el tipo penal (más en concreto, el legislador a través del tipo penal)? Y si es así, ¿cuándo puede igualarse? Ante estas cuestiones surgen dos opiniones doctrinales. Para quienes sostienen que la diferencia entre una y otra es exclusivamente formal, no se exigirán más requisitos a la omisión que a la acción, salvo la demostración de la relación de causalidad, de carácter naturalístico, imposible de establecer en la omisión, pues como sostiene la mayoría de la doctrina ex nihilo nihil fit, para que la omisión pueda ser igualada a la acción será

40 Vid. Muñoz Conde, Francisco/García Arán, Mercedes, Derecho Penal. Parte General, cit., p. 240.

41 La práctica totalidad de los tipos de resultado se formulan expresamente por el legislador como prohibiciones, pero esto no quiere decir que ese mismo resultado no se pueda producir por una omisión, conducta calificada como tal cuando infringe no la norma prohibitiva explicitada en el tipo, sino la preceptiva que subyace al tipo. El resultado desvalorado viene descrito a través de una norma de prohibición, en la que no se menciona expresamente el comportamiento omisivo como posible vía ilícita para llegar a aquél. En este sentido se puede ver Cuadrado Ruiz, M. ${ }^{a}$ Ángeles, "La comisión por omisión como problema dogmático", en ADPCP 1997, p. 390. 
necesario demostrar la imputación objetiva del resultado a esa omisión, así como los demás elementos de la parte subjetiva del tipo. Sin embargo, quienes defienden que la distinción formal entre acción y omisión responde a una diferencia material, consideran que la equivalencia entre acción y omisión no se puede hacer automáticamente. Para que la conducta que infringe una norma de mandato contenida en un tipo prohibitivo pueda ser igualada a la conducta activa, en su "desvaloración", ha de cumplir unos especiales requisitos. En el fondo, lo que se está diciendo, es que la norma de mandato y la norma de prohibición reflejan distintos deberes, que no son intercambiables, y que las conductas que las infringen tampoco pueden ser igualadas sin más ${ }^{42}$. A partir

42 Esta idea aparece reflejada con claridad en Octavio De Toledo y Ubieto, Emilio/Huerta Tocildo, Susana, Derecho penal. Parte General: Teoría jurídica del delito, cit., p. 572, al señalar que "como es obvio, dada la existencia de esos delitos menos graves de omisión propia en los que la producción de un resultado naturalístico es intrascendente, no todo quebrantamiento de un general deber de actuar en evitación de un resultado típico (por ejemplo, la muerte de una persona que se encuentra en peligro manifiesto y grave de morir) es calificable de comisión por omisión y, en consecuencia, equiparable al hacer positivo que ocasiona ese mismo resultado típico. Lo que es lógico si se piensa que para conminar con igual pena dos comportamientos distintos (el activo y el omisivo) es menester que posean un equivalente contenido de lo injusto: algo que no es posible afirmar en todo caso cuando por ejemplo, se compara el comportamiento de quien intencionadamente dispara y da muerte a otro y el de quien se encuentra a un sujeto malherido por el disparo fallido de un tercero que pretendió matarle y, en lugar de auxiliarle para evitar el peligro de muerte que corre, pasa de largo sin prestarle asistencia alguna. Estas son dos situaciones en principio desiguales que no pueden ser igualmente tratadas en todo caso (...) sin vulnerar el principio de justicia material y el de proporcionalidad. Ello significa que para equiparar punitivamente la omisión de una actuación, indiscriminadamente impuesta por el ordenamiento al efecto de evitar la producción de ciertos resultados, con la causación de los mismos, producto de un comportamiento activo, es absolutamente preciso que, además de la infracción del deber genérico de actuar que toda omisión típica comporta, concurra un plus que permita salvar la distancia que en principio separa la no evitación del resultado típico de su efectiva causación. Un plus del que nada nos dicen las normas incriminadoras contenidas en la Parte especial de la ley penal en las que, supuestamente, se encuentra integrada, junto con la comisión, la omisión impropia. (...) A partir de NAgLeR quedó firmemente establecido en la doctrina alemana que ese plus que permite imputar objetivamente el resultado a quien no lo ha evitado con su activa intervención, viene dado por la especial posición de garantía respecto al bien jurídico en riesgo de ser atacado en la que algunos omitentes (no todos) se hallan y de la que nace un deber de actuar jurídicamente impuesto a quien la ocupa". A esta postura la denomina Dopico Gómez-Aller, Jaсово, Omisión e injerencia en Derecho penal, cit., pp. 681, 689 s., "sintomática", señalando que "ha intentado hallar los 'síntomas' o rasgos externos comunes a toda omisión comisiva. En este sentido, ha determinado que las omisiones merecedoras de pena igual o similar a la del tipo activo son aquellas que infringen un deber de determinadas características ('especial', 'de garante', etc.); y ha procedido a establecer una agrupación tipológica de los casos en los que se dan deberes de esas características. Así, ha habido una amplia coincidencia en señalar la llamada tríada clásica (deber legal, contractual o derivado de injerencia) (sic.); y un consenso menor alrededor de otras tipologías (deber derivado de 'comunidades de peligro', 'confianza especial', etc.). (...) en estas doctrinas, las situaciones de hecho calificables como 'posiciones de garante' operan como rasgos externos de todas aquellas omisiones evaluables como 'omisiones impropias'. Se dice: será comisión por omisión la omisión si se dan estas circunstancias fácticas (posición de garante por deber legal, o por 
de aquí se construye la teoría de la posición de garante como elemento puente que permite llegar a desvalorar la omisión de la misma manera que la acción y atribuirle idénticas consecuencias jurídicas.

Sobre los requisitos exigidos para igualar una acción a una omisión, hablando así de comisión por omisión, se han desarrollado dos grandes teorías. La primera de ellas, mayoritaria, es la teoría de la posición de garante ${ }^{43}$, la segunda es la denominada teoría de la creación 0 incremento del riesgo ${ }^{44}$ (también se puede identificar una teoría intermedia, que exige tanto una posición de garante como la constatación de la identidad entre acción y omisión ${ }^{45}$ ).

contrato, o por conducta previa)... pero no explica el fundamento, más allá de vagas menciones a un desvalor similar al de la comisión activa".

43 Cuadrado Ruiz, M. ángeles, "La comisión por omisión como problema dogmático", cit., p. 455; Octavio De Toledo y Ubieto, Emilio/Huerta Tocildo, Susana, Derecho penal. Parte General: Teoría jurídica del delito, cit., pp. 565, 578, señalan que "a la parte objetiva del tipo de lo injusto del delito de omisión impropia pertenecen los elementos ya analizados al estudiar el tipo objetivo de la omisión propia"; Gómez Pavón, Pilar, "La responsabilidad del médico por omisión", en PJ 40-1995, 295; Silva Sánchez, Jesús María, "Omisión", cit., p. 970; Maqueda Abreu, María Luisa/Marín De Espinosa Ceballos, Elena, en: Zugaldía Espinar, José Miguel/Pérez Alonso, Esteban Juan, Derecho penal. Parte General, cit., pp. 802 SS.

44 Luzón Peña, Diego-Manuel, "Ingerencia, comisión por omisión y omisión de socorro (Comentario a la STS 24-4-1974)", en RDCir 1974, pp. 269 ss.; el mismo, "La participación por omisión en la jurisprudencia reciente del TS", en PJ 2-1986, pp. 79 ss.; una exposición crítica y detallada de cada una de las teorías explicativas de la comisión por omisión puede verse en Luzón PeÑA, Diego-Manuel، "Omisión impropia o comisión por omisión. Cuestiones nucleares: imputación objetiva sin causalidad, posiciones de garante, equivalencia (concreción del criterio normativo de la creación o aumento de peligro o riesgo) y autoría o participación", en Libertas, Revista de la Fundación Internacional de Ciencias Penales 6-2017, pp. 153 ss. Véase tb. este autor manteniendo esta postura en Luzón Peña, Diego-Manuel, "Omisión impropia o comisión por omisión. Cuestiones nucleares: imputación objetiva sin causalidad, posiciones de garante, equivalencia (concreción del criterio normativo de la creación 0 aumento de peligro o riesgo) y autoría o participación", cit., p. 175; Díaz y García Conlledo, Miguel, "Omisión de impedir delitos no constitutiva de participación por omisión: ¿un caso de dolo alternativo?", en PJ 24-1991, p. 208; Gimbernat Ordelg, Enrioue, "Causalidad, omisión e imprudencia", cit., pp. 29 ss.; el mismo, "La omisión impropia en la dogmática penal alemana. Una exposición", cit., pp. 99 ss.; el mismo, "El delito de omisión impropia", en RDPCr 4-1999, pp. 525 ss.; Paredes Castañón, José Manuel, El riesgo permitido en Derecho penal (Régimen jurídico-penal de las actividades peligrosas), cit., p. 238.

45 Silva Sánchez, Jesús María, El delito de omisión. Concepto y sistema, cit., pp. 342, 347, 359 s., 369 ss., manifiesta su concepto de comisión por omisión señalando que "sólo mediante la búsqueda de elementos de 'identidad' con la comisión en las omisiones equiparables es posible obtener una solución restrictiva, y, por ello conforme con el principio de legalidad, en este círculo de problemas. Así, cabría establecer una distinción entre omisiones que muestran una identidad estructural con la comisión y aquéllas que no. Identidad estructural de la que la posición de garante del sujeto omitente es elemento necesario pero no suficiente. El criterio dogmático de la identidad estructural -una vez concretado su contenido- permitirá, precisamente, superar la inseguridad y ambigüedad derivadas 


\section{La participación en comisión por omisión}

A la hora de establecer criterios que permitan determinar cuándo a una conducta omisiva se le puede imputar el resultado lesivo, es decir, cuándo nos encontramos ante una comisión por omisión, generalmente se está pensando en conductas de autoría ${ }^{46}$, y no se discute si es posible o no la apreciación de la participación en comisión por omisión, y si es posible, qué criterios se han de utilizar, si los mismos u otros distintos. No obstante, el silencio no es absoluto; podemos encontrar distintas soluciones a partir de las teorías que acabamos de exponer ${ }^{47}$.

Desde la teoría de la posición de garante no existe una respuesta unitaria sobre la posibilidad de apreciar participación en comisión por omisión. Al contrario, las respuestas son extremadamente contradictorias. Para unos, la condición de garante de un sujeto determina automáticamente que se le atribuya el resultado lesivo como autor del mismo aunque el hecho haya sido causado por un tercero; es decir, no cabe apreciar participación en comisión por omisión ${ }^{48}$. Para otros, al garante que omite pero no domina el hecho se le puede atribuir una responsabilidad como partícipe omisivo ${ }^{49}$. Por último, una posición "intermedia" ${ }^{50}$ niega, en general, la participación en comisión por omisión del garante, salvo en determinados delitos en los que de no ser calificado

del seguimiento exclusivo de consideraciones valorativas. A la vez, explicará por qué determinadas omisiones de sujetos en situaciones de responsabilidad intensificada parecen especialmente graves y, por ello, merecedoras de la misma pena que la creación activa de riesgo de producción del mismo resultado lesivo"; el mismo, "La responsabilidad penal del médico por omisión", cit., pp. 133 s.; Cuadrado Ruiz, M. a Ángeles, "La posición de garante", en ADPCP 2000, p. 20.

46 Cfr. Díaz y García Conleedo, Miguel, “Omisión de impedir delitos no constitutiva de participación por omisión: ¿un caso de dolo alternativo?", cit., p. 209.

47 Sobre un análisis detallado de esta cuestión véase Luzón Peña, Diego-Manuel, “Omisión impropia o comisión por omisión. Cuestiones nucleares: imputación objetiva sin causalidad, posiciones de garante, equivalencia (concreción del criterio normativo de la creación o aumento de peligro o riesgo) y autoría o participación", cit., pp. 179 ss.

48 Cfr. Octavio De Toledo y Ubieto, Emilio/Huerta Tocildo, Susana, Derecho penal. Parte General: Teoría jurídica del delito, cit., pp. 322 ss.; Bacigalupo Zapater, Enrique, Principios de Derecho Penal. Parte General, cit., p. 185; Kaufmann, Armin, Dogmática de los delitos de omisión, Madrid, Marcial Pons, 2006, pp. 297 ss.

49 Cfr. Rodríguez Mourullo, Gonzalo, La omisión de socorro en el Código Penal, Madrid, Tecnos, 1966, pp. 380 ss.; Córdoba Roda, Juan/Rodríguez Mourullo, Gonzalo, Comentarios al CP, t. I, Barcelona, Ariel, 1972, pp. 892 ss.; Maurach, Reinhart/Gössel, Karl Heinz/Zipf, Heinz, Derecho Penal. Parte General 2: Formas de aparición del delito y las consecuencias jurídicas del hecho, Buenos Aires, Astrea, 1995, $\S 47$ 111; Jescheck, Hans Heinrich/Weigend, Thomas, Tratado de Derecho Penal. Parte General, Granada, Comares, 2002, pp. 688 ss.

50 Siguiendo la denominación de Luzón Peña, Diego-Manuel, "La participación por omisión en la jurisprudencia reciente del TS", cit., p. 78. 
como partícipe quedaría exento de toda responsabilidad penal, pues no puede ser considerado autor (delitos de propia mano, especiales, de mera actividad, etc.) ${ }^{51}$. Desde la teoría de la creación o incremento del riesgo se ha tachado de incongruente la postura de quienes, defendiendo la posición de garante, conciben la posibilidad de la participación en comisión por omisión ${ }^{52}$. Desde esta postura se acude nuevamente al criterio de la identidad estructural y material entre conducta activa y omisiva. Es decir, para que una omisión pueda ser equivalente a una conducta activa de participación, debe cumplir los mismos requisitos que esta última ${ }^{53}$. Por lo tanto, no sólo se admite, sino que se reconoce claramente la posibilidad de calificar la conducta de un sujeto como participación en comisión por omisión. Pero esto no implica que haya que modificar el criterio que nos permite decir que la conducta omisiva es equivalente en el caso a una conducta activa. El criterio es el mismo para conductas de autoría y participación, la "creación o incremento del riesgo", la cuestión de si esa conducta es de participación o de autoría habrá que dilucidarla atendiendo a otros criterios. Por ejemplo, siguiendo la teoría de la determinación objetiva y positiva del hecho ${ }^{54}$,

51 Cfr. Roxin, Claus, Autoría y dominio del hecho en Derecho penal, 2. ${ }^{\text {a }}$ ed., Madrid, Marcial Pons, 2000, pp. 476 ss.; Stratenwerth, Günter, Strafrecht, Allgemeiner Teil, l: Die Straftat, 4. ${ }^{\text {a }}$ ed., München, Heymanns, 2000, § 1420 ss.; el mismo, Derecho Penal, Parte General, I: El hecho punible, Madrid, Edersa, 1982, § 14 1075; Cramer, Peter/Heine, Günter, en Schönke, Adolf/Schröder, Horst, StgB,

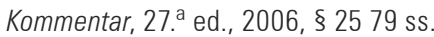

52 Luzón Peña, Diego-Manuel, “La participación por omisión en la jurisprudencia reciente del TS”, cit., p. 86.

53 Cfr. Luzón Peña, Diego-Manuel, "La participación por omisión en la jurisprudencia reciente del TS", cit., p. 87; Díaz y García Conlledo, Miguel, "Omisión de impedir delitos no constitutiva de participación por omisión: ¿un caso de dolo alternativo?", cit., pp. 208 ss.

54 Esta teoría es propuesta por primera vez en Luzón PeñA, Diego-Manuel, "Autoría e imputación objetiva en el delito imprudente: valoración de las aportaciones causales (Comentario a la STS 27-1-1984)", en RDCir 1984, pp. 275 ss., pero el estudio fundamental es Luzón Peña, Diego-Manuel, "La 'determinación objetiva del hecho'. Observaciones sobre la autoría en delitos dolosos e imprudentes de resultado", en ADPCP 1989, pp. 889 ss. (publicado también en Derecho Penal de la Circulación. Estudios de la jurisprudencia

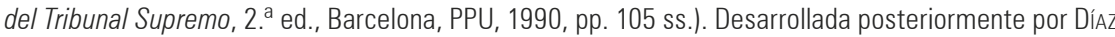
y García Conlledo, Miguel, La autoría en Derecho Penal, Barcelona, PPU, 1991, pp. 625, 688 ss. La primera exposición en conjunto y por escrito de su teoría está en Luzón Peña, Diego-Manuel/Díaz y García Conlledo, Miguel, "Determinación objetiva y positiva del hecho y realización típica como criterios de autoría", en RDPC 2003-2, pp. 89 ss., que se corresponde con la versión colombiana del artículo publicado en alemán: Luzón Peña, Diego-Manuel/Díaz Y García Conlledo, Miguel, "Objektive positive Tatbestimmung und Tabestandsverwirklichung als Täterschaftsmerkmale", en FS- Roxin, 2001, pp. 575 ss. Esta teoría es defendida y desarrollada también por: De Vicente Remesal, Javier/Díaz y García Conlledo, Miguel, "Autoría o participación en determinados supuestos de 'vigilancia' (Comentarios a la STS 21-2-1989) (Pte. Bacigalupo Zapater)", en PJ 27-1992 (comentario tercero), p. 209; Paredes Castañón, José Manuel, en Paredes Castañón, José Manuel/Rodríguez Montañés, Teresa, El caso de la colza: responsabilidad penal por productos adulterados o defectuosos, Valencia, Tirant lo Blanch, 1995, p. 149; Olaizola Nogales, Inés, El delito de cohecho, Valencia, Tirant lo Blanch, 1999, p. 174; Roso Cañadillas, Raquel, Autoría y 
si el riesgo creado o incrementado ha decidido el si y el cómo del hecho, entonces esa conducta omisiva es de autoría, en caso contrario, si cumple con los requisitos propios de alguna de las formas de participación, será una conducta de cooperación 0 complicidad o inducción en comisión por omisión.

\section{Regulación legal de la comisión por omisión: el art. 11 CP}

Actualmente, la comisión por omisión se encuentra regulada en el art. $11 \mathrm{CP}$, que dispone: "Los delitos que consistan en la producción de un resultado sólo se entenderán cometidos por omisión cuando la no evitación del mismo, al infringir un especial deber jurídico del autor, equivalga, según el sentido del texto de la Ley, a su causación. A tal efecto se equiparará la omisión a la acción: a) Cuando exista una específica obligación legal o contractual de actuar. b) Cuando el omitente haya creado una ocasión de riesgo para el bien jurídicamente protegido mediante una acción u omisión precedente".

Hasta la entrada en vigor del CP de 1995, la comisión por omisión no estaba regulada expresamente en el CP españo| ${ }^{55}$. El legislador español decidió introducir en la Parte General del CP una cláusula relativa a la comisión por omisión, solución adoptada también por la práctica totalidad de los Códigos Penales de otros países que precedieron al español en la regulación de esta materia ${ }^{56}$.

participación imprudente, Granada, Comares, 2002, pp. 580 ss.; Durán Seco, Isabel, La coautoría en Derecho Penal: aspectos esenciales, León, Secretariado de publicaciones y medios audiovisuales de la Universidad de León, 2003, pp. 45 ss.; García Mosouera, Marta, La estafa de seguro, Madrid, La Ley, 2006, p. 256; Rodríguez Vázouez, Virgilıo, Responsabilidad penal en el ejercicio de actividades médicosanitarias, Madrid, Marcial Pons, 2012, pp. 371 s.

55 Antes de llegar a la regulación expresa de la comisión por omisión en el CP actual, se intentó incluir ésta, con diferentes redacciones, en diversos proyectos de reforma de CP que precedieron al vigente. Sobre esta evolución se puede consultar Silva Sánchez, Jesús María, El nuevo Código penal: cinco cuestiones fundamentales, Barcelona, Bosch, 1997, pp. 52 ss.; el mismo, en Cово DeL Rosal, Manuel (dir.), Comentarios al Código penal I, Madrid, Edersa, t. I, 1999: arts. 1-18, pp. 458 ss.; sobre la evolución histórica de la comisión por omisión en España se puede consultar CuAdRAdo Ruiz, M. ángeles, "La comisión por omisión como problema dogmático", cit., pp. 431 ss.; Dopico Gómez-Aller, Jacobo, Omisión e injerencia en Derecho penal, cit., p. 678; Luzón Peña, Diego-Manuel, “Omisión impropia o comisión por omisión. Cuestiones nucleares: imputación objetiva sin causalidad, posiciones de garante, equivalencia (concreción del criterio normativo de la creación o aumento de peligro o riesgo) y autoría o participación", cit., pp. 183 ss.

56 Cfr. Silva Sánchez, Jesús María, El nuevo Código penal: cinco cuestiones fundamentales, cit., pp. 52 s.; el mismo, en Совo Del Rosal, Manuel (dir.), Comentarios al Código penal I, cit., p. 443, quien señala que "cláusulas similares a la que nos ocupa, al menos en cuanto a su propósito, se encuentran en el Derecho penal alemán, el austriaco, el italiano o el portugués. No, en cambio, en otros, como el francés 0 el inglés. (...) Dejando aparte el precepto italiano, la influencia del modelo alemán es patente en todos los demás, incluido el español"; Cuadrado Ruiz, M. a Ángeles, "La posición de garante", cit., pp. 441 s., considera que "el actual movimiento de reforma del Derecho penal parece mostrarse partidario de la conveniencia de consagrar legislativamente el principio básico que permite equiparar 
La redacción del art. $11 \mathrm{CP}$ presenta una serie de problemas interpretativos que en mi opinión se condensan en dos ámbitos de discusión. En primer lugar, se discute sobre el art. $11 \mathrm{CP}$ en sí mismo considerado, es decir, sobre la necesidad o no de su introducción, o lo que es lo mismo, sobre la necesidad o no de la regulación de la comisión por omisión a través de una cláusula general como la contemplada en la redacción final del citado artículo. Esta primera discusión pone en relación el art. 11 CP con el principio de legalidad. Por otra parte, el segundo ámbito de polémica se refiere a su contenido, ya que tal y como aparece redactado, es susceptible de diversas y, hasta se podría llegar a decir, opuestas interpretaciones.

Respecto a la primera cuestión, es decir, el art. 11 CP en relación con el principio de legalidad, se han desarrollado, básicamente, dos posturas diferentes. Un sector doctrinal, frente a quienes mantienen el carácter determinante de la identidad estructural entre acción y omisión, consideraba tradicionalmente necesaria la regulación legal, a través de alguna fórmula escrita en el CP, de la comisión por omisión $n^{57}$. Lo contrario,

la comisión por omisión a la comisión activa. Así lo han hecho no sólo el ordenamiento alemán en el parágrafo 13 del StGB, sino también el parágrafo 2 del öStGB y el art. 40 del CP italiano, entre otros. También aparecen recogidos en el art. 13 del CP brasileño, en el art. 10 del CP portugués y en el art. 1.2 del proyecto polaco. Y el ordenamiento español se ha sumado a esta tendencia. No así, los ordenamientos francés o inglés"; Dopico Gómez-Aller, JacoBo, Omisión e injerencia en Derecho penal, cit., p. 678, señala cómo "algunos ordenamientos parecen haber acogido expresamente esta concepción de la comisión por omisión, conforme a la cual el conductor del tranvía que por no frenar atropella a alguien no le mata, pero realiza una conducta de gravedad idéntica o similar; por lo que es necesario crear una 'cláusula de equivalencia' que permita penar la omisión como si fuese una acción. Posiblemente sea el caso del § 13 del Código penal alemán, el § 2 del austriaco 0 el art. 40 del italiano".

57 Octavio De Toledo y Ubieto, Emilio/Huerta Tocildo, Susana, Derecho penal. Parte General: Teoría jurídica del delito, cit., p. 577, antes de la actual redacción del CP sostenían que "Ios delitos de comisión por omisión chocan frontalmente con las exigencias derivadas del principio de legalidad: tanto en su aspecto formal como en el material. Y tal situación no hallará remedio auténtico hasta tanto no se proceda a la tipificación expresa, a través de su descripción singularizada en la Parte especial, de las hipótesis punibles de comisión por omisión"; HuerTA Tocildo, Susana, Problemas fundamentales de los delitos de omisión, cit., pp. 72, 145 ss., 186, a partir de esta reflexión plantea una doble vía para regular expresamente la comisión por omisión, o bien a través de una cláusula general o bien a través de un sistema de numerus clausus, al indicar, "dado que, a mi juicio, el tipo del delito omisivo impropio no está contenido en la misma norma de la Parte especial en la que sí lo está sin duda alguna el delito comisivo, es absolutamente preciso, si no se quiere llegar a la conclusión-incompatible con las exigencias mínimas del principio de legalidad penal- de que es un tipo no escrito en su totalidad, que se le incluya en una norma legal que le sería así específica. Lo que se puede hacer de dos maneras diversas: 0 a través de un sistema de 'cláusula general' referida a la norma de la Parte especial relativa al delito comisivo, o a través de numerus clausus de delitos omisivos impropios". Sobre las ventajas e inconvenientes de una y otra fórmula, se ocupa en las páginas 145 ss., para llegar a la conclusión de que el mejor sistema sería el de la tipificación de la comisión por omisión a través de un sistema de numerus clausus, señalando que "1) es mejor contar con una cláusula general en la que no se expresen las posiciones de garantía, que permanecer en la silenciosa actitud 
la aplicación de los tipos de la Parte Epecial pensados y redactados para conductas activas a supuestos de conductas omisivas, supondría un quebranto del principio de legalidad ${ }^{58}$.

Desde otro sector doctrinal, representado por quienes defienden la identidad estructural y material entre la omisión y la acción ${ }^{59}$ como la vía que permite calificar una conducta omisiva como comisión por omisión y así equipararla a la acción, se

de nuestro CP en materia de comisión por omisión; y 2) es mejor que esa cláusula general contenga el elenco de posiciones de garantía -por más imperfecta que sea su expresión- que la indeterminación legal de ese elemento. El siguiente paso es obvio: 3) es mejor un sistema de numerus clausus de tipos omisivos impropios que cualquier sistema de cláusula general". Sobre la oportunidad o no de uno u otro sistema, se pronuncia, ya a posteriori, es decir, una vez entrado en vigor el CP de 1995, CuAdRado Ruiz, M. ángeles, "La posición de garante", cit., pp. 454 s., indica que "sin predeterminar aún las bondades 0 incorrecciones que deparará el art. $11 \mathrm{CP}$, podría adosarse, ulteriormente, un sistema de numerus clausus en la Parte especial, conforme al cual el legislador determinase el ámbito de figuras delictivas respecto de las cuales 'se autoriza ex lege la identificación normativo-estructural' entre omisión y realización activa del tipo". Sin embargo, concluye, "igualmente considero correcto el hacerlo mediante una cláusula en la Parte general del CP. La propuesta de añadir, ulteriormente, un sistema de numerus clausus en la Parte especial, conforme al cual el legislador determinase el ámbito de figuras delictivas respecto de las cuales 'se autoriza ex lege la identificación normativo-estructural' entre omisión y realización activa entiendo que su expresión sería un tanto reiterativa en tanto en cuanto la naturaleza de los delitos de comisión por omisión está referida a este tipo de delitos".

58 Cuadrado Ruiz, M. a Ángeles, "La posición de garante", cit., pp. 441, 454, 455, afirma que "en todo caso, la fórmula del art. 11 supone una superación de una laguna legal: si se había dicho muchas veces que como la omisión no es nada, nada puede causar, el precepto elimina ese impedimento"; "quizá el art. 11 sea un texto ambiguo, criticable en su redacción concreta, pero lo que no se puede discutir es que, por lo menos, ofrece al intérprete y al aplicador del Derecho penal una fórmula que le oriente a la hora de tomar una decisión. La positivación de una cláusula general del tipo del art. 11 CP ha supuesto, por primera vez en nuestra historia penal, el 'traje legal' de la comisión por omisión, lo que considero un avance, a pesar de la objeciones que se le puedan hacer al precepto"; "me parece una decisión de política legislativa acertada el proceder a una regulación legal expresa de la figura dogmática de la comisión por omisión. De esta forma se 'completa' el sistema jurídico-penal proclamado en los artículos 1 y $10 \mathrm{CP}$ en relación con el principio de legalidad, salvando así las posibles objeciones al respecto"; Muñoz Conde, Francisco/García Arán, Mercedes, Derecho Penal. Parte General, cit., pp. 242 s., consideran que "en el art. 11 se pretende resolver este problema [scil. lo que aquí se plantea es si el sujeto que no actúa, deja de hacer u omite, responde también de la muerte, la defraudación, el hurto o la violación] con una fórmula que, como luego se verá, no está exenta de objeciones, pero que en todo caso ofrece a la praxis una base legal y unas directrices para que, cuando llegue el caso, pueda resolverlo sin recurrir a criterios extralegales o puramente doctrinales que pueden infringir el principio de legalidad. Quizás el art. 11 sea criticable en su redacción concreta, pero lo que no se puede discutir es que, por lo menos, ofrece al intérprete y al aplicador del Derecho penal una fórmula que le oriente a la hora de tomar una decisión".

59 Se debe tener en cuenta que aquí se incluyen tanto los representantes de la teoría de la creación 0 incremento del riesgo, como aquellos otros autores que sostienen una posición que se puede calificar de mixta, por cuanto exigen una posición de garante pero, en todo caso, realizan un razonamiento de identidad para poder equiparar a todos los efectos penales una conducta omisiva a una conducta activa. 
consideraba que no era necesaria la inclusión de una cláusula general como la del art. 11 CP para regular esta figura, y en muchos casos se entendía que un artículo de esta índole, lejos de ayudar a esclarecer cuándo a una conducta omisiva se le puede imputar un resultado y castigarse igual que una acción, acabaría por dificultar en exceso este proceso, distorsionando el propio concepto de comisión por omisión ${ }^{60}$. Al contrario que la posición anterior, aquí el punto de partida es que omisión y acción deben ser igualmente desvaloradas si se dan en ellas determinados requisitos de "desvaloración" y de imputación del resultado. Pero estos requisitos son o debieran ser los mismos para las dos. No hay por qué exigir nada especial a la conducta omisiva, identificable con la activa, puesto que ambas infringen un mismo deber jurídico. De ahí se deduce que las omisiones pueden ser subsumibles en los tipos de la Parte Especial del CP, aunque aparentemente, en su redacción formal, éstos se refieran a conductas activas ${ }^{61}$. Y ello porque el tipo incluye tanto una norma de prohibición como su reverso, una norma de mandato, por lo que puede ser infringido por una conducta activa u omisiva indistintamente. De esta manera, no se podría hablar en ningún caso de una ruptura con el principio de legalidad, ni de un quebranto del principio in dubio pro reo, pues las conductas estarían tipificadas, con todos sus requisitos, en los delitos contenidos en la Parte Especial del CP.

La segunda cuestión polémica tiene que ver con el contenido y significado material del art. 11 CP. La duda fundamental estriba en saber por cuál de las teorías de la comisión por omisión desarrolladas dogmáticamente se inclina el legislador de 1995. La cuestión no debería plantear mayores dificultades; sin embargo, dada la redacción final del artículo, no está claro si asume la teoría de la posición de garante, la teoría de la creación o incremento del riesgo o si adopta una posición mixta.

60 En este sentido, Silva Sánchez, Jesús María, El nuevo Código penal: cinco cuestiones fundamentales, cit., pp. 59 s., 64; el mismo, en Coвo Del Rosal, Manuel (dir.), Comentarios al Código penal I, cit., pp. 452, 457 s., al plantear tres vertientes de opinión sobre la conveniencia o no de la regulación expresa en el CP de la comisión por omisión, se refiere al último punto de vista en los siguientes términos: "(...) el de quienes entendían que la situación en el marco del Código derogado era perfectamente sostenible desde perspectivas de principio de legalidad y que ni la tipificación expresa en la Parte especial ni la inclusión de una cláusula genérica en la Parte general del CP eran necesarias, pudiendo incluso reportar más inconvenientes que ventajas"; "a mi entender, una cláusula general como la del nuevo art. 11 CP no era necesaria"; Dopico Gómez-AlLer, JacoBo, Omisión e injerencia en Derecho penal, cit., p. 682, señala que "el art. 11 CP no es necesario para sancionar este tipo de conductas, puesto que ya pueden ser sancionadas con base en un tipo penal que diga 'el que matare a otro será castigado con la pena $X^{\prime \prime \prime}$; sobre esta cuestión, véase también Luzón Peña, Diego-Manuel, “Omisión impropia o comisión por omisión. Cuestiones nucleares: imputación objetiva sin causalidad, posiciones de garante, equivalencia (concreción del criterio normativo de la creación o aumento de peligro o riesgo) y autoría o participación", cit., p. 184.

61 Así, Silva Sánchez, Jesús María, El nuevo Código penal: cinco cuestiones fundamentales, cit., pp. 60 ss.; el mismo, en Совo Del Rosal, Manuel (dir.), Comentarios al Código penal l, cit., pp. 452 ss. 
La teoría de la posición de garante está presente en este artículo en dos momentos. En el primer párrafo, con la expresión "al infringir un especial deber jurídico del autor", y en el segundo párrafo, "a tal efecto se equiparará la omisión a la acción: a) Cuando exista una específica obligación legal o contractual de actuar. b) Cuando el omitente haya creado una ocasión de riesgo para el bien jurídicamente protegido mediante una acción u omisión precedente". Según la primera expresión, este artículo parece exigir una posición de garante en el sujeto que omite para poder, al menos, entrar a analizar si tal omisión es o no equiparable a la acción. Desde una posición de garante pura se llega incluso a considerar que la equivalencia que exige el propio art. $11 \mathrm{CP}$ se agota en la infracción de un especial deber jurídico, siempre que se dé alguno de los requisitos del párrafo segundo. Es decir, la infracción de un especial deber jurídico implicaría ya de por sí la equivalencia según el sentido del texto de la Ley.

La teoría de la creación o incremento del riesgo, que exige una identidad estructural y material entre omisión y acción, también parece haber "ganado" su parcela en el art. $11 \mathrm{CP}$, "aunque plasmada en el Código con una terminología 'más débil" "62, ya que el CP no utiliza el término "identidad", sino que utiliza el término "equivalga". No obstante, a pesar de esta diferencia terminológica, la doctrina reconoce ${ }^{63}$, en general, que se trata de una plasmación de la teoría de la identidad y que se debe entender en este sentido.

Atendiendo a lo visto, se puede concluir que el art. $11 \mathrm{CP}$ se inclina por la teoría mixta, y en este sentido se interpreta por la doctrina ${ }^{64}$. El art. $11 \mathrm{CP}$ es el resultado de

62 Cfr. Cuadrado Ruiz, M. ángeles, "La comisión por omisión como problema dogmático", cit., p. 443; Silva Sánchez, Jesús María, El nuevo Código penal: cinco cuestiones fundamentales, cit., p. 66; el mismo, en Cobo Del Rosal, Manuel (dir.), Comentarios al Código penal l, cit., p. 460.

63 Cfr. Vives Antón, Tomás S. (coord.), Comentarios al Código Penal de 1995, t. I, Valencia, Tirant lo Blanch, 1996, 84 ss.; Cuadrado Ruzz, M. ángeles, "La comisión por omisión como problema dogmático", cit., p. 443; Silva Sánchez, Jesús María, El nuevo Código penal: cinco cuestiones fundamentales, cit., p. 66; el mismo, en Cobo Del Rosal, Manuel (dir.), Comentarios al Código penal I, cit., p. 460; Gimbernat Ordeig, Enrioue, "El delito de omisión impropia", cit., pp. 533 s.; Morales Prats, Fermín, en Quintero Olivares, Gonzalo/Morales Prats, Fermín/Prats Canut, Josep Miquel, Manual de Derecho Penal. Parte General, 3. ${ }^{a}$ ed., Pamplona, Aranzadi, 2002, p. 381; Dopico Gómez-Aller, Jacobo, Omisión e injerencia en Derecho penal, cit., pp. 692 ss.

64 Cfr. Silva Sánchez, Jesús María, El nuevo Código penal: cinco cuestiones fundamentales, cit., p. 68; el mismo, en Cobo Del Rosal, Manuel (dir.), Comentarios al Código penal I, cit., pp. 464 s., concluye: “En resumen, el nuevo art. $11 \mathrm{CP}$ acoge, simultáneamente, dos modelos contrapuestos de fundamentación de la comisión por omisión. Por un lado, el modelo que la construye a partir de la comisión activa, sobre la base de consideraciones de identidad estructural y entendiendo, por tanto, que comisión por omisión y comisión activa constituyen un idem normativo (lo que se refleja en las estructuras de imputación). Por otro lado, el modelo que la construye partir de la omisión pura, entendiendo que la comisión por omisión es una omisión meramente cualificada por la concurrencia de un deber jurídico específico de evitar el resultado"; así también, Dopico Gómez-Aller, JacoBo, Omisión e injerencia en Derecho penal, cit., p. 698. 
combinar los requisitos de cada una de las teorías relativas a la comisión por omisión, de manera que la exigencia de una posición de garante es el primer criterio que se debe tener en cuenta para tratar de determinar si nos encontramos ante una comisión por omisión; sirve para reducir el espectro de sujetos a los que, en una situación dada, se les puede exigir actuar y, por lo tanto, a los que se les puede exigir responsabilidad por el resultado producido ante su inactividad, pero es necesario completar el análisis con la comprobación de una equivalencia con la acción típica, equivalencia entendida como identidad estructural y material entre ambas. Se exige, por lo tanto, un "doble juicio".

\section{La distinción entre omisión, acción e infracción del deber de cuidado}

Después de todo lo visto, aún cabe preguntarse sobre la necesidad de la distinción entre acción y omisión, y, en todo caso, de la importancia que esta distinción pueda tener. Obviamente, la respuesta a estas cuestiones será diferente según cuál sea la postura adoptada de las expuestas anteriormente. Quienes consideran que existe una diferencia material entre ambas, al entender que cada una de estas formas de conducta implica una infracción distinta del deber, concluyen que el desvalor de una y otra conducta será diferente. Algo que se refleja posteriormente en la concepción de la comisión por omisión, ya que siguiendo tal línea argumental exigirán ciertos requisitos específicos a la conducta omisiva para llegar a igualarla a la activa (teoría de la posición de garante). Desde este punto de vista, la distinción entre omisión y acción es de vital importancia, ya que las consecuencias jurídicas también son diferentes. Por su parte, quienes sostienen que la diferencia entre ambas formas de comportamiento es exclusivamente formal (en atención a la concreta formulación de la norma jurídica con la que se compare aquélla) y que entre ambas no se puede decir que haya una diferencia de contenido (no implican un distinto ataque al deber jurídico subyacente en la norma penal, común a ambas) no atribuyen mayor importancia a tal distinción ${ }^{65}$.

65 Paredes Castañón, José Manuel, El riesgo permitido en Derecho penal (Régimen jurídico-penal de las actividades peligrosas), cit., p. 206, considera que "desde una perspectiva plenamente normativista, como la aquí propugnada, se entiende que el ordenamiento jurídico, haciendo abstracción de diferencias reales innegables entre las diversas conductas humanas (diferencias que no se dan tan sólo entre conductas 'activas' y 'omisivas', sino también entre otros muchos modos de comportamiento, lo que no impide que todos ellos sean tratados también de forma prácticamente uniforme a efectos de determinación de la antijuridicidad), pero jurídicamente irrelevantes (precisamente, en nuestro caso, porque en nada cambia la significación jurídica de la conducta según que, por ejemplo, la misma sea o no causal en sentido naturalístico respecto del resultado, si se da el requisito jurídicamente exigido: la imputación objetiva, en este caso), establece criterios unificados de juicio (con alguna excepción) de los comportamientos. Desde este punto de vista, pues, toda diferenciación será siempre lógicamente posterior al juicio jurídico -único- de valor sobre la conducta, constituyendo aquella tan sólo una simple clasificación, sin gran trascendencia práctica -sí teórica-. Y podremos 
En materia de comisión por omisión consideran que lo relevante será determinar si la omisión cumple los mismos requisitos que la acción para considerarla antijurídica, sin exigir ningún requisito especial para subsumir aquélla en el mismo tipo penal que ésta (teoría de la creación o incremento del riesgo).

Como es lógico, desde esta última postura, la utilidad de la distinción entre omisión y acción no tiene tanta relevancia ${ }^{66}$ como desde otras perspectivas se le ha querido dar. No obstante, se admite la posible y "necesaria" distinción entre ambas, coincidiendo así, finalmente, en la necesidad de buscar criterios que permitan dicha diferenciación ${ }^{67}$. Las razones que se alegan para ello son diversas. Existen razones de corte sociocultural, en el sentido de que la percepción social que se tiene de conductas activas y omisivas es distinta ${ }^{68}$. Por otra parte, el método utilizado para vincular un

hablar, sí, también de 'conductas activas' y de 'conductas omisivas', como traslación al objeto del juicio del contenido del deber, activo u omisivo, conforme al cual se juzga; e igualmente, podremos calificar un determinado tipo de injusto como -predominantemente- activo u omisivo. Pero ello, por sí mismo, no cambiará nada por lo que se refiere a las consecuencias que ha de tener el juicio jurídico sobre la conducta. De este modo, se invierte el modo de razonar: pues, en vez de calificarse el delito de activo o de omisivo por tipificar una acción o una omisión respectivamente, es el carácter 'activo' u 'omisivo' del tipo de injusto (del contenido del deber de conducta) el que caracteriza la conducta en uno u otro sentido. Todo ello, además, viene reforzado, como veremos, porque en la inmensa mayoría de los casos (los tipos activos y de comisión por omisión) los tipos penales recogen bajo un solo enunciado y una única formulación del deber de conducta comportamientos que podrían ser calificados como comisivos y como omisivos. Desde este punto de vista, pues, la diferenciación comisión/omisión queda profundamente relativizada, al menos en su significación jurídico-penal".

66 Así, Paredes Castañón, José Manuel, El riesgo permitido en Derecho penal (Régimen jurídico-penal de las actividades peligrosas), cit., pp. 248, 253, entiende que "dicha diferenciación es tan sólo una distinción de carácter pragmático, basada en consideraciones de conveniencia técnico-legislativa, que carece, sin embargo, prácticamente de significación por lo que se refiere al modo de operar en la determinación de la antijuridicidad".

67 Silva Sánchez, Jesús María, El delito de omisión. Concepto y sistema, cit., p. 174, en este sentido señala que "ni siquiera las tesis aparentemente más radicales en este punto consiguen eludir la necesidad de una distinción conceptual entre comisión y omisión, sea cual fuere el elemento 0 extremo determinante en este sentido. Cuestión diferente, como ya se advirtió, es la trascendencia o importancia que se asigne a la distinción en la teoría del delito. Desde diversos puntos de vista se ha examinado este tema en términos de relativizarlo. Pero todo ello, como se verá, sin pretender negar una cierta influencia a la diferenciación que ahora nos ocupa. Más bien se trata de oponerse a su presentación como fundamental".

68 Así, Silva Sánchez, Jesús María, El delito de omisión. Concepto y sistema, cit., p. 174, recoge el pensamiento de algunos autores en este sentido: "Simplificando mucho su postura, en la que el análisis ético llega incluso a predominar sobre el jurídico, advierte Nino la existencia de una convicción intuitiva general, según la cual las omisiones serían menos malas que los actos positivos perjudiciales y 'sólo las omisiones que se dan en el contexto de ciertas relaciones normativas particulares son moralmente asimilables a tales actos positivos'. Con todo, constata un progresivo descrédito filosófico de la idea de que la omisión es menos grave que el hacer positivo"; Paredes Castañón, José Manuel, El riesgo permitido en Derecho penal (Régimen jurídico-penal de las actividades peligrosas), cit., pp. 248, 253, 
resultado a una conducta activa u omisiva difiere, al menos, respecto a la relación de causalidad ${ }^{69}$. Además, el calificar una conducta como activa u omisiva parece que puede tener repercusiones en relación con otras categorías o elementos del delito ${ }^{70}$. Finalmente, esa distinción puede afectar a la determinación de la responsabilidad ${ }^{71}$.

señala que "por lo que se refiere a la utilidad de dicha distinción, y aunque, en mi opinión, tal y como ya he manifestado, la misma no me parece de tanta relevancia como habitualmente se viene sosteniendo, lo cierto es que existen al menos dos razones para intentarla. La primera es que, por mucha identidad normativa entre ambos grupos de delitos que queramos predicar, lo cierto es que tanto lingüísticamente como en el pensamiento vulgar existe una innegable diferenciación entre conductas activas y omisivas, tocada además de claras connotaciones valorativas. Y parece lógico pensar que muy probablemente tal diferenciación atienda a rasgos distintivos reales, que sería útil conocer".

69 Tal y como pone de manifiesto, Gimbernat Ordelg, Enrloue, "Causalidad, omisión e imprudencia”, cit., pp. $15 \mathrm{s.}$ al indicar que "a pesar de las dificultades que existen para determinar si un comportamiento ha de ser considerado activo u omisivo, la solución (...) del problema parece que no se puede eludir, dado que, según la doctrina dominante, los presupuestos de la imputación del resultado son distintos en cada una de las dos clases de comportamiento. Mientras que en el comportamiento activo doloso 0 imprudente para la imputación del resultado se requeriría (y bastaría con) que aquél hubiera causado científico naturalmente éste (con las limitaciones, naturalmente, que impone el criterio de la imputación objetiva), en la omisión, en cambio, los presupuestos de la responsabilidad por un resultado serían otros: por una parte, que el omitente tuviera posición de garante, y, por otra, que la acción omitida, con una probabilidad rayana en la certeza, hubiera evitado el resultado [o según otra tesis, minoritaria, hubiera disminuido el riesgo de lesión]"; Gómez Rivero, Carmen, La responsabilidad penal del médico, cit., p. 346, afirma que "si realmente existiera una escrupulosa equivalencia entre los presupuestos de la responsabilidad activa y omisiva la trascendencia de la discusión orientada a depurar uno y otro supuesto no pasaría de su interés teórico. Sin embargo, es lo cierto que tanto los distintos métodos de comprobación de la relación de causalidad entre la conducta y el resultado en una y otra tipología de delitos, así como la forma en que se delimite la posición de garantía como presupuesto del juicio de responsabilidad por omisión, determina la conveniencia de depurar, también a efectos prácticos, el injusto reconducible, respectivamente, a una conducta activa u omisiva".

70 En este sentido, Silva Sánchez, Jesús María, El delito de omisión. Concepto y sistema, cit., pp. 176 s. entiende que "en todo caso sería obligado aceptar que la elección conduce a regímenes diversos en cuanto a aspectos de la teoría de la participación, de la tentativa, etc.... Que en absoluto carecen de significación y por sí solos justificarían todo esfuerzo encaminado a una más clara diferenciación".

71 Lo que advierten, Silva Sánchez, Jesús María, El delito de omisión. Concepto y sistema, cit., pp. 176 s., para quien a pesar de que "todas las afirmaciones anteriores son probablemente ciertas [scil. relativa importancia de la distinción entre acción y omisión]. Según se señala, pues, en cierto número de casos la distinción entre comisión y omisión carecerá de efectos en cuanto a responsabilidad. Sin embargo, ello no parece suficiente para negar trascendencia a la opción por una u otra clase de realizaciones típicas. En primer lugar, porque para muchos supuestos es posible seguir manteniendo que dicha opción viene seguida de consecuencias que afectan directamente a la responsabilidad"; Paredes Castañón, José Manuel, El riesgo permitido en Derecho penal (Régimen jurídico-penal de las actividades peligrosas), cit., pp. 248, 253, indicando que "ya hemos visto que la identidad normativa entre delitos activos y delitos omisivos, siendo fundamentalmente cierta, no lo es de forma absoluta; puesto que existe un grupo de delitos omisivos que se diferencia del resto de los delitos por sancionar el incumplimiento de mandatos de mejorar situaciones jurídicas, y por exigir dicho cumplimiento 
Por lo tanto, independientemente de la trascendencia que se le quiera dar a la diferencia entre acción y omisión (algo que tiene especial repercusión en materia de comisión por omisión), y del valor (material o formal) que ésta tenga, ante una conducta concreta, en un supuesto real, es necesario preguntarse sobre el método 0 criterios que nos permitan decidir si nos encontramos ante una conducta activa $u$ omisiva. Si en general ésta es una cuestión difícil ${ }^{72}$, todavía presentará más dificultades cuando haya que dirimirla en relación con conductas imprudentes. Desde luego, el desarrollo dogmático de cada una de estas instituciones, imprudencia y omisión, específicamente en su modalidad de comisión por omisión, ha abonado el terreno para que crezca la posibilidad de confundirlas ${ }^{73}$. Como ejemplo claro del paralelismo entre ambas nos encontramos con la naturaleza jurídica con la que hoy se conciben omisión e imprudencia y con el "trayecto" dogmático seguido para llegar hasta aquí. Tanto la imprudencia como la omisión se consideran, mayoritariamente, conceptos normativos. Profundizando en esta línea, y desde la teoría de la posición de garante, se establece una conexión entre el deber de garante (propio de la comisión por omisión) y el deber de cuidado (propio de la imprudencia), hasta llegar en ocasiones a confundirlos ${ }^{74}$. Por ejemplo, se dice que deber de garante y deber de cuidado comparten, en determinados casos, el presupuesto que los origina, que no es otro que la preexistencia de un peligro que obliga al sujeto a actuar, 0 a actuar en un determinado sentido. No han faltado quienes consideran que todo delito imprudente es un delito omisivo, y esto como consecuencia de haber formulado tradicionalmente el delito imprudente como "omisión del cuidado debido", o bien, "omisión de la diligencia debida"75. Precisamente

con unos límites específicos (individualizados y no normativos). Ello hace también interesante, a mi entender, profundizar en los posibles rasgos distintivos entre delitos activos y omisivos".

72 En este sentido, Silva Sánchez, Jesús María, El delito de omisión. Concepto y sistema, cit., pp. 177 s.

73 Los puntos de contacto entre omisión e imprudencia son ampliamente desarrollados por Corcor Bidasolo, Mirentxu, El Delito imprudente. Criterios de imputación del resultado, cit., pp. 74 ss.

74 Sobre la confusión entre deber de garantía y deber de cuidado, ampliamente en Lascurain Sánchez, Juan Antonio, La protección penal de la seguridad e higiene en el trabajo, Madrid, Civitas, 1994, pp. 236 ss.

75 Advierten esta posible confusión, Silva Sánchez, Jesús María, El delito de omisión. Concepto y sistema, cit., p. 204, según el cual "el impropiamente denominado -se señala- 'elemento omisivo' de la imprudencia vendría dado por la infracción de la norma de cuidado. En efecto, a menudo, para designar a ésta se utiliza el término omisión: así, por ejemplo, omisión del cuidado debido". Muchos de los que defienden el modelo de la omisión para explicar las conductas activas y omisivas, llegan a esta conclusión. No me voy a detener en la explicación de estas concepciones por haber sido tratada por otros autores. Una explicación pormenorizada de cada una de las formulaciones doctrinales del modelo de la omisión y de cómo determinadas teorías llegan a la conclusión de que todo delito imprudente es un delito omisivo se puede ver en Paredes Castañón, José Manuel, El riesgo permitido en Derecho penal (Régimen jurídico-penal de las actividades peligrosas), cit., pp. 231 ss. Este autor 
es a esta formulación a la que ciertos autores atribuyen el solapamiento que entre delitos imprudentes y conductas omisivas se suele producir en los pronunciamientos de la jurisprudencia española ${ }^{76}$. Esta confusión se puede dar todavía utilizando la

señala como "en la doctrina de raíz más antigua es lugar común considerar que, al menos en los delitos no dolosos, la esencia de la infracción del deber de conducta consiste en una omisión de carácter psicológico. Se habla así de una acción interna, omisión de la previsión debida, vicio de intelecto y/o voluntad, omisión de la diligencia necesaria (para prever y evitar), desconocimiento del carácter ilícito de la conducta. Y, a diferencia de los delitos dolosos -se dice-, lo común a delitos activos no dolosos y a delitos omisivos estriba en que su esencia está constituida por la infracción de un deber de conducta. (...) Un segundo modelo es aquel que se centra en argumentaciones de tipo causal, concretamente, a partir de la fórmula de la 'conditio sine qua non'. De acuerdo con la misma, es causa de un resultado aquel factor cuya supresión hipotética implica necesariamente la desaparición, también hipotética, del resultado. A tenor de ello, se afirma que el resultado disvalioso se deriva, no tanto de la acción positiva -aparentemente causante-, sino más bien de la omisión de la diligencia debida que a ella acompaña. Puesto que la acción positiva, realizada con la diligencia debida adecuada, no hubiera producido por sí misma el resultado disvalioso; es, por lo tanto, la omisión - de la diligencia debida- el factor fundamental en la causación de dicho resultado. Nos encontraríamos, pues, aquí ante un delito de omisión". También se puede encontrar una exposición crítica de estas posiciones en Corcoy BIDAsolo, Mirentxu, El Delito imprudente. Criterios de imputación del resultado, cit., pp. 64 ss.

76 Cfr. Arroyo Zapatero, Luis, La protección penal de la seguridad en el trabajo, Madrid, Servicio Social de Higiene y Seguridad del Trabajo, 1981, p. 133; Silva Sánchez, Jesús María, El delito de omisión. Concepto y sistema, cit., p. 204, indica que "no parece necesario poner de relieve las confusiones a que ello puede dar lugar. Un ejemplo singular lo constituye la Jurisprudencia de nuestro TS que, sistemáticamente, utiliza para referirse a la infracción del deber de cuidado frases de terminología omisiva: así, por ejemplo, 'con omisión de las más elementales precauciones (...)' entre otras muchas"; Corcoy Bidasolo, Mirentxu, El Delito imprudente. Criterios de imputación del resultado, cit. p. 65; Gómez Rivero, Carmen, La responsabilidad penal del médico, cit., p. 348; Villacampa Estiarte, Caroulna, Responsabilidad penal del personal sanitario. Atribución de responsabilidad penal en tratamientos médicos efectuados por diversos profesionales, Pamplona, Aranzadi, 2003, p. 195. En especial Alastuey Dobón, María del Carmen, “Delitos de comisión por omisión en la jurisprudencia del Tribunal Supremo", en ADPCP 1992, pp. 989, 1019, afirma que "en todos los delitos culposos el autor no debe haber observado el cuidado objetivamente debido, debe haber omitido la observación de ese cuidado. Pero esta omisión, que existe en todos los delitos culposos, tanto si se han cometido por acción como por omisión, no debe confundirse con la omisión entendida como no-acción; ésta sólo puede (y debe) darse en los delitos imprudentes por omisión y es independiente de la observancia del cuidado objetivamente debido. La distinción anteriormente citada es obvia. Sin embargo, algunas de las sentencias del TS resultan confusas en este sentido ya que, aun tratándose de supuestos de delitos imprudentes en comisión por omisión, cuando el TS utiliza el término 'omisión' se refiere a omisión del cuidado objetivamente debido y no a omisión de acción. Por otro lado, el TS no da un tratamiento diferenciado a los delitos culposos por omisión respecto a los cometidos por acción salvo en algunas sentencias muy recientes, las cuales representan una mínima parte dentro de las numerosísimas sentencias referidas al tema. Lo expuesto en los párrafos anteriores puede dar una idea de lo difícil que resulta descifrar la verdadera intención del TS en algunas de sus sentencias. (...) Tradicionalmente, nuestro TS ha confundido, en los delitos de comisión por omisión culposos, la omisión de acción con la omisión de la observancia del cuidado objetivamente debido, lo que ha impedido un tratamiento jurisprudencial satisfactorio de estos delitos. El trato indiferenciado entre delitos de acción y de omisión al que anteriormente hacía referencia, se ha mantenido en los delitos culposos hasta nuestros días". 
104 Revisión de los conceptos de acción, misión y comisión por omisión. Un análisis a través de casos -

Virgilio Rodríguez Vázquez

expresión "infracción del deber de cuidado" como elemento nuclear y caracterizador de la imprudencia, tal y como advierten JAKOBS ${ }^{77}$, Roxin ${ }^{78}$ y Luzón PeÑ̃A ${ }^{79}$.

Pues bien, para determinar si una conducta es activa u omisiva se han desarrollado multitud de teorías: la "teoría del punto central de la reprochabilidad", la teoría del "sentido social" 80 , las tesis pragmáticas ${ }^{81}$, la teoría del movimiento corporal" ${ }^{82}$, la teoría de la "aplicación de energía" 83 o el criterio de la causalidad. Además de éstas, en

77 Jakobs, Günther, Derecho Penal, Parte General, Fundamentos y teoría de la imputación, 2. ed., Madrid, Marcial Pons, 1997, § 9/6, señala que "por lo que se refiere a la supuesta existencia de un deber de cuidado o de una infracción de cuidado que caracterice la imprudencia, en ésta no hay -como en el dolo- más deber que el que surge de la norma, y sólo este deber se infringe: en la comisión imprudente, el autor debe omitir el hecho, y en la omisión imprudente debe realizarlo (icuidadosamente!). Sobre todo en el delito de comisión, lo que se suele decir de que el autor ha dejado de observar el cuidado prescrito es falso desde el punto de vista de la lógica de las normas: en el delito de comisión el autor no es que deba obrar cuidadosamente, sino que debe omitir el comportamiento descuidado. Ejemplo: en el ámbito de la comisión no se prescribe manejar las cerillas con cuidado, sino que se prohíbe el manejo descuidado: no existe un deber de manejar".

78 Roxin, Claus, Allgemeiner Teil, t. I: Grundlagen. Der Aufbau der Verbrechenslehre, cit. (Derecho penal, Parte General, t. I: Fundamentos. La estructura de la teoría del delito, cit.), § 24 12, señalando que "el elemento de la infracción del deber de cuidado no conduce más allá que los criterios generales de imputación. Es más vago que éstos y por tanto prescindible. En rigor es incluso 'erróneo desde el punto de vista de la lógica de la norma', pues produce la impresión de que el delito comisivo imprudente consistiría en la omisión del cuidado debido, lo que sugiere su interpretación errónea como un delito de omisión. Sin embargo, al sujeto no se le reprocha el haber omitido algo, sino el haber creado un peligro no amparado por riesgo permitido y sí abarcado por el fin de protección del tipo, que se ha realizado en un resultado típico".

79 Vid. Luzón Peña, Diego-Manuel, Curso de Derecho Penal. Parte General, cit., p. 500; el mismo, Lecciones de Derecho Penal. Parte General, cit., nm. 31/35 ss.

80 Cfr. Silva Sánchez, Jesús María, El delito de omisión. Concepto y sistema, cit., p. 181, según el cual "ambas compartirían la idea que la distinción entre hecho comisivo y hecho omisivo no es una cuestión fáctica, sino valorativa, normativa. Según ello, debe olvidarse el lado externo del comportamiento, la idea de movimiento corporal, que no es sino un correlato del naturalismo. Aunque haya causación activa de un resultado, es, pues, posible entender el proceso más bien como una no evitación del resultado".

81 Cfr. Silva Sánchez, Jesús María, El delito de omisión. Concepto y sistema, cit., p. 185, destaca que "ante un supuesto equívoco o ambiguo, en caso de duda debe optarse por la calificación comisiva: in dubio pro commissione".

82 Con una base ontológica, entiende la acción y la omisión como conceptos prejurídicos, identificando a la primera con el movimiento corporal y a la segunda con la pasividad. Pero esta forma de distinguir una y otra no resulta satisfactoria, pues desconoce que la omisión (concepto normativo) consiste (o casi siempre consistirá) en un movimiento corporal en una dirección distinta a la exigida desde el Derecho. Cfr. Silva Sánchez, Jesús María, El delito de omisión. Concepto y sistema, cit., p. 186.

83 Cfr. Silva Sánchez, Jesús María, El delito de omisión. Concepto y sistema, cit., pp. 186 s. Según esta teoría "el hacer supone la aplicación de energía en una determinada dirección, mientras que el omitir implica la no-aplicación de energía en determinada dirección. Pero esta diferenciación 
relación con el delito imprudente una posible vía de explicación es la que hace pivotar la diferencia entre una y otra forma de conducta sobre el llamado "momento omisivo". Desde este punto de vista, se considera que en toda conducta o comportamiento imprudente existe, desde la perspectiva jurídicopenal, un "momento omisivo"84, y será la mayor o menor relevancia que se le otorgue al mismo lo que permita calificar una conducta como omisiva o como activa. En los supuestos en los que el "momento omisivo" no alcance la entidad suficiente como para ser considerado de forma aislada, nos encontraremos ante una acción imprudente. Si, por el contrario, es el momento omisivo lo relevante, hablaremos de una conducta omisiva. La calificación de una conducta en uno u otro sentido es, por lo tanto, el resultado de un proceso de valoración objetiva de la misma ${ }^{85}$, y tal calificación dependerá de a cuál de los dos aspectos de la conducta (positivos o negativos) se le dé más importancia en el caso concreto ${ }^{86}$. De esta forma se pretende distinguir entre el momento omisivo de la acción imprudente,

aparentemente tan clara, se advierte, en sí misma, vacía de sentido en cuanto se trata de ponerla en práctica. En efecto, a partir del concepto negativo y transitivo (limitativo) de omisión, resulta posible, prácticamente en cualquier momento de la vida del hombre, decir que actúa y omite a la vez. Pues, evidentemente, aplica energía en una determinada dirección y, al hacerlo, deja de aplicarla en todas las direcciones alternativas incompatibles con aquélla. Esta es una 'realidad ontológica'. Para decidir con qué aspecto del todo ontológico nos quedamos, cuál de ellos es el relevante, el que nos va a permitir calificar el hecho del sujeto como comisión u omisión, resulta ineludible adoptar un punto de vista determinado, una referencia externa a la propia estructura óntica. (...) la referencia es normativa y viene dada, concretamente, por la tipicidad penal".

84 Cfr. Gómez Rivero, Carmen, La responsabilidad penal del médico, cit., p. 345, considera que "el momento normativo de la imprudencia descansa en la infracción del deber de cuidado, infracción que se traduce a la postre en el desconocimiento, en la ignorancia y, en definitiva, en la omisión de las pautas de comportamiento que exige la lex artis. Justamente por ello, porque a la estructura conceptual de la imprudencia es implícita un momento de dejación de lo exigible y, en definitiva, un momento omisivo, no es de extrañar que no pocas veces se planteen supuestos limítrofes entre la acción imprudente y la omisión impropia, de tal suerte que dependiendo de cómo se enuncie la ilicitud del comportamiento, la infracción de la norma de cuidado se presta a reconducirse a una u otra posibilidad".

85 Cfr. Gómez Rivero, Carmen, La responsabilidad penal del médico, cit., p. 345, considera que "sólo cuando a partir de una contemplación objetiva de los hechos pueda predicarse desde un punto de vista valorativo la autonomía de la omisión frente a la conducta activa y situarse en un momento secuencialmente distinto del inicial comportamiento activo del agente, tiene sentido plantearse las bases de responsabilidad conforme a los esquemas de un delito de omisión impropia".

86 Cfr. Paredes Castañón, José Manuel, El riesgo permitido en Derecho penal (Régimen jurídico-penal de las actividades peligrosas), cit., p. 219, al exponer este teoría desde la concepción del deber de conducta señala que "sostienen los defensores de este criterio que lo que varía entre ambos grupos de delitos y de deberes de conducta es más bien el énfasis que se pone en uno y otro aspecto a efectos de determinar el desvalor objetivo de la conducta: en el caso de los delitos omisivos, en la realización de una actuación; en el caso de los delitos activos, en las medidas - de cuidado- que acompañan a dicha actuación". 
de la omisión propiamente dicha. Como resultado de tal proceso de valoración se llega a la conclusión de que en la acción, lo omisivo, es decir, aquello que se deja de hacer y que revela una falta de cuidado, tiene un carácter adjetivo, califica a la conducta activa, que es la que realmente constituye el ataque al bien jurídico, lo sustantivo. Cuando el momento omisivo adquiere autonomía propia frente a lo activo, pasa a convertirse en lo sustantivo y, en definitiva, en el objeto principal de enjuiciamiento. Sin embargo, esta teoría ha encontrado un importante rechazo por diversas razones ${ }^{87}$, especialmente porque en la acción imprudente el momento omisivo nunca puede ser elevado a la categoría de omisión, porque el cuidado no es una acción sino algo que se predica de una acción: acción y cuidado guardan una relación de sujeto-predicado $0^{88}$, de manera que la falta de cuidado siempre depende de una conducta activa y no puede ser vista como una omisión. Respecto a esta última argumentación hay que señalar que siendo cierta la idea de que en la acción imprudente el "momento omisivo" es algo que se predica de la acción, es decir, adjetiva a aquélla, no es del todo cierto que el cuidado no sea una acción o que el "momento omisivo" no pueda elevarse a la categoría de omisión, ya que el cuidado no es sino el resultado de un conjunto de conductas de acción y de abstención ${ }^{89}$, y como ya señalé, está en la valoración del mismo el determinar si se mantiene con un carácter adjetivo o adquiere categoría de principal (sustantivo).

De todos los criterios desarrollados por la doctrina para tratar de determinar cuándo nos encontramos ante una conducta activa u omisiva, al que más se recurre, acogido además mayoritariamente ${ }^{90}$, es el de la causalidad. Bien entendido en

87 Cfr. Silva Sánchez, Jesús María, El delito de omisión. Concepto y sistema, cit., p. 205, recoge las siguientes razones: "Que esa omisión, aun cuando existiera, sería en todo dependiente del hacer. Sólo a través de éste se relacionaría con el resultado. Además, entender que la infracción del deber de cuidado constituye una omisión supondría convertir todas las imprudencias activas en omisivas"; además, "las prohibiciones no sólo prescriben la no realización de determinadas acciones. Al contrario, a menudo, sobre la base de que se actúa, prescriben la realización de acciones en determinada forma (son mandatos de actuar de modo determinado: cuidadoso). Los mandatos propiamente dichos, en cambio, ordenan simplemente actuar, sin más".

88 Vid. Arroyo Zapatero, Luis, La protección penal de la seguridad en el trabajo, cit., p. 133; Silva Sánchez, Jesús María, El delito de omisión. Concepto y sistema, cit., p. 205; Corcoy Bidasolo, Mirentxu, El Delito imprudente. Criterios de imputación del resultado, cit., p. 69.

89 Vid. Silva Sánchez, Jesús María, El delito de omisión. Concepto y sistema, cit., p. 207; Paredes Castañón, José Manuel, El riesgo permitido en Derecho penal (Régimen jurídico-penal de las actividades peligrosas), cit., p. 220.

90 Cfr. Silva Sánchez, Jesús María, El delito de omisión. Concepto y sistema, cit., pp. 192, 199, 201; Bacigalupo Zapater, Enrioue, Principios de Derecho Penal. Parte General, cit., pp. 390 ss., afirma que "en los ejemplos de los que hemos partido [scil. los ejemplos son clásicos: el fabricante de pinceles que entrega pelos de cabra a sus obreros sin desinfectarlos, o el farmacéutico que expende un medicamento sin requerir la receta médica], la aplicación de este criterio [scil. criterio de la 
el sentido de que no se trata de demostrar la relación de causalidad de la acción ejecutada por el sujeto con cualquier consecuencia resultante de aquélla, sino de comprobar la relación de causalidad de dicha acción con el resultado típico: es así como este criterio despliega su operatividad a los efectos que nos interesa. Silva Sánchez lo expresa de la siguiente forma: "Es preciso apuntar que no se trata de cualquier causalidad, sino, concretamente, del proceso de causación del resultado típico. De este modo, el fundamento para hacer responsable a un sujeto por comisión será que su comportamiento haya causado el resultado expresado en el correspondiente tipo. (...) Así, se señala que quien, por un hacer activo, con determinados requisitos, causa el peligro de producción de la lesión de un bien jurídico, responde por la causación por un hacer. Ello con independencia de que, además, incumpla la obligación de evitar la lesión de bienes jurídicos ajenos ${ }^{\prime \prime 1}$. La aplicación de este método es relativamente

causalidad], conduce a la afirmación de una acción. El entregar pelos de cabra a los obreros y el expender el medicamento son causa del resultado porque, suprimiendo estas acciones mentalmente, aquél no se hubiera producido (conditio sine qua non). (...) En la práctica este criterio debe aplicarse mediante tres comprobaciones diferentes. En primer lugar debe establecerse si el autor ha dado impulso a la cadena causal que llevó al resultado. En segundo lugar habrá que verificar si este impulso es típico, antijurídico y culpable. Por último, y siempre y cuando no se trate de un hecho activo típico, antijurídico y culpable, cabrá preguntarse si haciendo lo que era posible el autor hubiera evitado el resultado". La inclusión de Mır Puig, Santiago, Derecho Penal. Parte General, cit., p. 308 s., en este sector doctrinal debe hacerse con matices, pues realmente parte de la consideración de que la diferencia entre acción y omisión es una diferencia normativa, según la clase de norma infringida, aunque admite el criterio de la causalidad, eso sí, con matices, como delimitador entre acción y omisión, lo que en definitiva supone admitir una diferencia ontológica entre ambas. Este autor señala como punto de partida que "en cuanto su estructura, mientras que los tipos de acción se realizan si se efectúa la conducta que describen, los tipos de omisión se refieren a la no verificación de una determinada conducta, por lo que se realizan si tiene lugar una conducta distinta a la prevista -en absoluto es necesaria la pasividad-. Por lo que afecta al distinto significado normativo de los tipos de acción y de omisión, mientras que los primeros (tipos de acción) son la base de la infracción de una norma prohibitiva de una intervención activa indeseable por su nocividad, los segundos (tipos de omisión), son la base de la infracción de una norma preceptiva, que obliga a una determinada cooperación deseable. El injusto del delito de acción consiste en una intervención activa nociva que en principio una norma prohíbe; el injusto de la omisión consiste en hacer algo distinto a la prestación deseable obligada en principio por una norma preceptiva. (...) El planteamiento propuesto, ampliamente compartido por la doctrina actual, ha de llevar a una consecuencia que a menudo se desconoce: si en Derecho penal la presencia de una omisión no depende del carácter físiconaturalístico de una conducta activa o pasiva, sino de la estructura del tipo y de su significado como base de la infracción de una norma penal preceptiva, no podrá decidirse la existencia de una omisión en el sentido del Derecho penal antes de contemplar el tipo legal. No hay para el Derecho penal una omisión que deba precederle. Por ello, la problemática de la omisión no puede tratarse como realidad que la ley presupone y se da con independencia de ella, sino sólo en el seno de la teoría del tipo de injusto, como una de sus modalidades según la clase de la norma que puede infringir -y no según la especie de la conducta-".

91 Silva Sánchez, Jesús María, El delito de omisión. Concepto y sistema, cit., p. 192, continúa, "en efecto, de no optarse por ese criterio de individualización, siempre sería posible decir que el sujeto interviene causalmente en unos procesos y no causalmente en otros, sin que cupiera concreción alguna. La 
sencilla. En el caso de que no exista relación de causalidad entre la conducta realizada por el sujeto y el resultado típico, concluiremos que no existe una conducta activa, existiendo una omisión pura o una comisión por omisión -si se cumplen los requisitos exigidos, en función de la teoría que se siga, para apreciar ésta-. Si, por el contrario, se confirma la relación de causalidad, podremos afirmar la existencia de una conducta activa, aunque esto no significa que también se pueda apreciar la concurrencia de una conducta omisiva ${ }^{92}$.

Atendiendo a esta reflexión, hay que advertir que en determinados casos, especialmente en los delitos imprudentes, puede que concurran conductas activas y omisivas, es decir, que es posible reconducir el resultado a una u otra forma de actuación. Pues bien, en estos casos, concurriendo ambas conductas en un mismo sujeto y sobre un mismo bien jurídico, se debe optar por resolver los casos a partir de la conducta activa.

\section{Análisis de las conductas de los profesionales sanitarios}

Los profesionales médico-sanitarios, al igual que cualquier otro profesional 0 que cualquier persona que interactúa con otros sujetos en sociedad, pueden cometer infracciones penales (imprudentes o dolosas, aunque mi objeto de estudio se centra en las conductas imprudentes, las que tienen más relevancia en este ámbito) tanto a través de conductas activas como de conductas omisivas. Inicialmente no se puede descartar ninguna de las dos opciones. El problema es determinar cuándo nos encontramos ante una u otra forma de actuación. Problema que, como ya anticipé, se ve acrecentado en conductas imprudentes. Por lo tanto, el proceso de identificación de una conducta como activa u omisiva en el ámbito médico-sanitario no es fácil. Además, no todos los autores siguen el mismo criterio para diferenciar conductas activas u omisivas en esta actividad, lo que dificulta aún más la tarea de identificación.

\subsection{Concepto "reducido" de la conducta médico-sanitaria: la estrati- ficación de la conducta médico-sanitaria}

Algunos autores ${ }^{93}$ consideran que en las imprudencias cometidas en el ámbito médico-sanitario es relativamente frecuente que concurran en un solo autor conductas activas, causantes del resultado, con conductas omisivas, que no

individualización -insistimos- puede producirse desde cualquier punto de vista. Tratándose, sin embargo, de conceptos jurídico-penales, la pauta debe venir dada por la tipicidad".

92 Vid. Silva Sánchez, Jesús María, El delito de omisión. Concepto y sistema, cit., p. 200.

93 Cfr. Gimbernat Ordelg, Enrioue, "Causalidad, omisión e imprudencia", cit., pp. 13 ss.; Hava García, Esther, La imprudencia médica, Valencia, Tirant lo Blanch, 2001, pp. 120 ss. 
impiden aquél ${ }^{94}$. Desde este punto de vista, la intervención médica imprudente se entiende como un complejo integrado por diversas conductas, unas activas y otras omisivas, todas ellas susceptibles de ser consideradas aisladamente. Para solucionar la cuestión de a cuál de ellas imputar el resultado (aparte de dilucidar en el caso de la omisión si se requiere o no la posición de garante) se utiliza un criterio temporal complementado con el principio de la prevalencia de la conducta activa, en caso de que el resultado lesivo pueda ser imputable a ambas conductas. Esta teoría y sus consecuencias se pueden ver a través de los siguientes ejemplos.

1. Un primer ejemplo es el de las transfusiones de sangre realizadas sin previa práctica de pruebas serológicas sobre el plasma sanguíneo transfundido ${ }^{95}$. Simplificando el caso real, en el que los médicos encargados de realizar las pruebas eran distintos de los médicos encargados de la transfusión, y suponiendo ahora que es un mismo médico el encargado de realizar dichas pruebas y de practicar la transfusión, se plantea la siguiente visión del supuesto. Se estratificaría la intervención del médico en dos conductas diferenciadas y aisladas. Una primera conducta de carácter omisivo sería la no realización de pruebas serológicas del plasma sanguíneo almacenado en el banco de hemoderivados del centro hospitalario. Una segunda conducta, diferenciada temporal y jurídicamente de la primera, sería la "transfusión" de la sangre a un paciente, conducta evidentemente activa. Así pues, en esa intervención médica, se distinguen dos conductas, una omisiva y una activa que, cronológicamente aparecen en este orden. Ante esta secuenciación de las conductas médicas, surge nuevamente la cuestión de a cuál de ellas se le debe imputar el resultado. La solución propuesta por algunos autores ${ }^{96}$ opta por imputar el resultado de muerte del paciente a la conducta activa, y esto por considerar que la conducta omisiva, a saber, no realizar pruebas serológicas en el plasma sanguíneo, no integra, en sí misma y aisladamente considerada, ningún tipo delictivo. Así, "mientras la sangre no se transfunda, no se está llevando a cabo ninguna omisión jurídico-penalmente relevante; el comportamiento adquiriría trascendencia desde esta perspectiva sólo mediante la acción: cuando el médico trasfunde (...). Es entonces cuando se consuma el delito imprudente por acción, ya que aquellas carencias de los medios con los que materialmente se causan los resultados imprudentes no son sino faltas de medidas de precaución que, por sí solas y sin un comportamiento activo, son inidóneas para ponerlas en relación con un

94 Cfr. Gimbernat Ordeig, Enrioue, "Causalidad, omisión e imprudencia", cit., pp. 13 ss.; Hava García, Esther, La imprudencia médica, cit., pp. 120 ss.

95 Cfr. STS 4-11-1991 (RJ 1991/6021).

96 Cfr. Gimbernat Ordeig, Enrique, "Causalidad, omisión e imprudencia", cit., pp. 13 ss.; Hava García, Esther, La imprudencia médica, cit., pp. 120 ss. 
resultado"97. En definitiva, nos encontraremos ante un delito de homicidio cometido a través de una acción imprudente.

2. En el caso del paciente que muere a consecuencia de la infección producida por una gasa que queda alojada en el interior de su cuerpo tras ser operado, se distinguen, desde esta posición, al menos dos conductas susceptibles de ser consideradas aisladamente: en primer lugar, la conducta de "introducir" la gasa en el cuerpo del paciente en un determinado momento de la operación y, posteriormente, la conducta de "no extraer" la gasa del cuerpo del paciente. "Introducir" la gasa se califica como una conducta activa, mientras que "no extraer" esa gasa se identifica con una conducta omisiva. Para decidir a cuál de estas dos conductas se le imputa el resultado hay que analizar cada una de ellas y comprobar, por separado, si cumplen los requisitos del tipo. Se considera que la primera conducta, activa, a pesar de que guarde una relación de causalidad con el resultado y de que, incluso, se le pueda imputar objetivamente, no cumplirá sin embargo, en la mayoría de los supuestos, la parte subjetiva del tipo, al faltar en el sujeto activo la intención de lesionar o matar, lo que excluye el dolo, y al ser la "introducción" de una gasa en el cuerpo del paciente una conducta, en la mayoría de los casos, ajustada al deber de cuidado, es decir, una acción correcta, se excluye también la imprudencia. Así las cosas, sólo se le puede imputar el resultado lesivo a la conducta omisiva, "no extraer" la gasa, que a la postre desemboca en una infección en el paciente. Si el resultado lesivo es imputable objetivamente a la omisión, algo que estará en función de la teoría seguida sobre la comisión por omisión, entonces el cirujano habrá cometido un delito de lesiones o un homicidio imprudente, según el caso, en comisión por omisión.

3. Por lo que se refiere al caso en el que el anestesista se ausenta del quirófano, en relación con la STS 4-11-1991 (RJ 1991/6021)98, GIMBERnAt OrdeIG llega a la siguiente solución: "Con razón, se condena por un homicidio imprudente en comisión por omisión: al anestesista, porque deja de vigilar al paciente que está siendo operado; al cirujano, porque si bien -y sobre la base del principio de división del trabajo, y para concentrarse en su propia actividad médica, no tiene que intervenir en las tareas propias del anestesista-, lo que sí que le incumbe, como director de la operación, es asegurar la presencia continua de aquél en el quirófano, por lo que si permite que se ausente, responderá igualmente de un homicidio en comisión por omisión"99.

97 Gimbernat Ordelg, Enrique, "Causalidad, omisión e imprudencia", cit., p. 20; en la misma línea, Hava García, Esther, La imprudencia médica, cit., p. 122.

98 Sentencia citada y comentada por Gimbernat Ordeig, Enrique, "Causalidad, omisión e imprudencia", cit., pp. $23 \mathrm{~s}$.

99 Gimbernat Ordeig, Enrioue, “Causalidad, omisión e imprudencia”, cit., pp. 23 s. 


\subsection{La delimitación entre acción y omisión a partir de la "contem- plación global" de la intervención sanitaria}

Aquí, el punto de partida para determinar cuándo nos encontramos ante una conducta activa y cuándo ante una conducta omisiva es entender la conducta médico-sanitaria en un sentido amplio. Frente a otras propuestas que llevan a cabo una secuenciación o división de una misma intervención médica en varios actos, que después pasan a calificar de activos u omisivos, cabe la posibilidad de concebir esa misma intervención médica de forma unitaria, como una sola conducta global, integrada por aspectos activos y pasivos. Desde este punto de vista, la intervención del médico sobre el paciente prácticamente se pasa a identificar con alguna de las fases de la atención sanitaria (diagnosis, anamnesis, prognosis y tratamiento), que el médico, por lo general, ejecutará, es decir, llevará a cabo "activamente", lo que ya da lugar a hablar de una acción. En dicha ejecución puede que no tome las medidas adecuadas, por ejemplo, no realice determinadas pruebas al paciente, olvide elementos extraños en el cuerpo del paciente, no adopte determinadas medidas de control, etc. Todos ellos serían aspectos negativos de una misma conducta activa, diagnosticar o aplicar un tratamiento. En definitiva, la apreciación de una conducta omisiva en este contexto será excepcional. En este sentido se expresa GómEz Rivero, advirtiendo "sólo cuando a partir de una contemplación objetiva de los hechos pueda predicarse desde un punto de vista valorativo la autonomía de la omisión frente a la conducta activa y situarse en un momento secuencialmente distinto del inicial comportamiento activo del agente, tiene sentido plantearse las bases de responsabilidad conforme a los esquemas de un delito de omisión propia. Lo contrario supondría convertir todas las imprudencias activas en omisiones, con la consiguiente limitación de la responsabilidad por hechos imprudentes a las personas que se encontrasen en una situación de garantía"100. Y más adelante, "la calificación del comportamiento como omisivo debe reservarse para los casos en que dicha omisión no se inserte en el contexto más amplio de una conducta activa, esto es, aquellos supuestos en que la dejación de la conducta exigible no se corresponda con la pasividad propia de la falta del deber de cuidado de un comportamiento activo"101. La aplicación de este criterio de delimitación y las soluciones a las que llega se puede ver a través de los siguientes grupos de casos, relativamente frecuentes en la práctica sanitaria.

1. Respecto a la intervención médica en fase de diagnóstico, se plantea la discusión sobre cómo se debe entender la conducta del médico que se equivoca en este momento de la asistencia al paciente, condicionando así el resultado lesivo. En algunas ocasiones, el TS opta por calificar de comisión por omisión la conducta del

100 Gómez Rivero, Carmen, La responsabilidad penal del médico, cit., pp. 348 s.

101 Gómez Rivero, Carmen, La responsabilidad penal del médico, cit., p. 352. 
médico que se equivoca en el diagnóstico, como se puede ver en la STS 726/1998, 22-1 (RJ 1999/275) y en la STS 811/1999, 25-5 (RJ 1999/5253).

El primer caso se trata de una embarazada que sufre fuertes dolores lumbares. El ginecólogo, ante el estado de la paciente, cuyo embarazo ya alcanzaba las treinta y ocho semanas de gestación, sin estar exento de ciertas complicaciones, pues en principio había sido gemelar, diagnosticó un cólico nefrítico, sin consultar a ningún urólogo u otro especialista con conocimientos más cercanos a la presunta patología. La paciente queda ingresada en la clínica y sometida al tratamiento correspondiente al cólico nefrítico diagnosticado. Se le practica análisis de orina y de sangre, así como una ecografía obstétrica, que indicaba una marcada disminución de líquido amniótico y obra abdominal y de gestación, lo que revelaba "trabajo de parto". No obstante, el ginecólogo insiste en su inicial diagnóstico y no realiza reconocimiento ginecológico alguno. Ante esta situación, la embarazada solicita a una matrona de la clínica dicho reconocimiento, a lo que aquélla accede. Este reconocimiento pone de manifiesto que la mujer se encontraba ya en una avanzada dilatación, por lo que la envió enseguida a la sala de partos, donde, con la asistencia del ginecólogo, se produce el parto en apenas media hora. El niño que dio a luz precisó de inmediata asistencia sanitaria para su reanimación, realizando el anestesista una intubación, siendo trasladado en ambulancia a la sección de neonatología del hospital más próximo, pese a lo cual, y ante la hipoxia cerebral sufrida, el niño termina padeciendo una encefalopatía crónica, con retraso en los patrones de maduración psicomotriz. En el fundamento de derecho segundo, el TS expone las razones que le llevan a entender la conducta del ginecólogo como una omisión: “(...) tampoco ofrece cuestión que el acusado omitió varias acciones que le eran debidas; así, en primer lugar, prescindió de consultar con un urólogo u otro especialista respecto a las molestias de que se quejaba la embarazada y ello le llevó, por dos veces, a hacer un diagnóstico equivocado, atribuyendo a un inexistente cólico nefrítico lo que eran dolores lumbares propios de 'trabajo de parto'; igualmente omitió el deber que le era inexcusable de reconocer ginecológicamente a la embarazada, especialmente ante los resultados que presentaban los análisis y la ecografía practicada; y en definitiva, omitió atender un parto en el momento en el que todos los síntomas lo hacían necesario. No había nada que restringiera o limitara su capacidad para realizar la acción que omitió y que le era exigible".

En cuanto a la segunda, se condena a un ginecólogo que no detecta una meningitis tuberculosa ante los síntomas evidentes que presentaba la embarazada, consistentes, en un primer momento, en tos, cansancio, apatía y pérdida de peso, y con el paso del tiempo, ya en sucesivas consultas, en el desarrollo de adenopatías en la zona latero cervical, incluso en sede de urgencias, vómitos y desmayos, que el médico atribuye (estos últimos) a intolerancia alimentaria por ingesta de una pizza. En el fundamento cuarto el TS realiza el siguiente razonamiento: "Aplicando al presente 
caso las anteriores pautas se observa que el acusado, que siguió médicamente a la mujer que ha sufrido las lesiones la atendía en su condición de ginecólogo-obstetra en el curso y evolución de un primer embarazo, viéndola y reconociéndola los días 21 de febrero, 28 de marzo y 2 de abril de 1995. En la primera ocasión, la gestante no presentaba aún la patología que, en cuanto a la aparición de adenopatías se desarrolló partir de mediados de marzo, aunque ya sí, antes, en ocasión de la visita del 21 de febrero, la mujer en gestación de 21 semanas, refirió apatía, tos, cansancio y pérdida de peso, constatada por el médico. En la siguiente visita de 28 de marzo, ya se le indicó al médico la presencia de las adenopatías, que debieron alertarle sobre la existencia de un proceso patológico no asociable normalmente con el embarazo, no obstante lo cual no procede a averiguar las causas y ello resulta grave en una zona del país en la que ya se había constatado la resurgencia significativa de casos de tuberculosis y están los médicos alertados sobre la posibilidad de encontrarse con casos de tal enfermedad, cuyos síntomas tampoco observó el recurrente, cuando la mujer fue ingresada de urgencia con un problema aparentemente gástrico, pero manteniendo la misma sintomatología general. El acusado señala que realizó todas las actividades que le pidió la paciente, pero es indudable que de un médico, especialista o no, se ha de tener una conducta activa de descubrimiento de síntomas y aplicación de terapias oportunas y adecuadas para contrarrestar las patologías que se encuentren. No lo hizo así el recurrente, en un caso en que los síntomas de las adenopatías eran ya evidentes en el cuello de la paciente y de la relevante significación en relación con todos los otros datos de sintomatología que se ofrecían (tos, cansancio, apatía, pérdida de peso) en un lugar donde ya era conocido entre el personal médico la recurrencia, antes desusada, de casos de tuberculosis, por lo que tal omisión ha de considerarse imprudencia grave los efectos de aplicar al caso el citado art. 152 CP".

Gómez Rivero rechaza la solución del TS interpretando que la calificación de la conducta del médico como omisión se hace sobre la ausencia de pruebas pertinentes, que, para ella, no son más que reflejo de una falta de cuidado de una conducta "activa": diagnosticar. Así, respecto a la primera sentencia señala: "El momento omisivo que el Tribunal destaca como fundamento de la omisión no es más que una secuencia propia de la conducta más amplia -activa- consistente en realizar un diagnóstico erróneo"102.

102 Gómez Rivero, Carmen, La responsabilidad penal del médico, cit., p. 350. A continuación "el médico, en efecto, confunde los dolores de un parto con los de un cólico nefrítico; y por ello, porque ha errado en esa calificación, omite realizar pruebas ulteriores que estarían indicadas si sus sospechas fuesen de otro diagnóstico. Resulta de esta forma que esa omisión no es más que la consecuencia lógica de una actuación negligente previa más amplia que le lleva a confundir un parto con los síntomas de un simple cólico. Y desde luego, una vez que lo confunde, la no verificación de las pruebas que habrían de confirmar un diagnóstico distinto no es más que la consecuencia lógica del error previo 0, si se quiere, no es más que la proyección del diagnóstico erróneo que el médico realiza de forma activa. Exigirle que actúe correctamente es pedirle que no se confunda en el diagnóstico. Y esa confusión representa un comportamiento activo, no omisivo". 
Respecto a la segunda, opina: "Una vez más, la imprudencia que deduce el Tribunal se vincula a la omisión de pruebas en fase de diagnóstico. Sin embargo, no por ello dicha omisión puede reconducirse a un delito de lesiones en comisión por omisión. Porque, insisto una vez más, la omisión consistente en la no prescripción de las comprobaciones que hubieran revelado la enfermedad que realmente sufría la paciente no es más que la consecuencia de un diagnóstico activo negligente. Y es que pertenece a la lógica misma de las cosas que cuando se diagnostica una enfermedad se omitan pruebas para avanzar en el diagnóstico de otra distinta"103.

2. Un segundo grupo de casos es el de las transfusiones sanguíneas, en especial, el "caso del sida", resuelto por la STS 18-11-1991 (RJ 1991/9448), en el que se condena al director del centro hospitalario y a la jefa del servicio de hematología por la realización de transfusiones de sangre sin someterla a la pruebas de detección de anticuerpos del sida. Entiende que la conducta relevante es la transfusión, es decir, una conducta activa, mientras que la falta de pruebas de la sangre no es más que un descuido en la realización de aquélla.

3. Por lo que se refiere a los supuestos de operaciones quirúrgicas en las que el cirujano olvida una gasa o un instrumento hemostático en el interior del cuerpo de un paciente, Gómez Rivero considera que "esa dejación de un hacer no es el fundamento de su eventual responsabilidad por un delito de omisión impropia; es simplemente, el aspecto omisivo de una infracción de deber más amplia que tacha como imprudente a la contemplación global de la maniobra activa que representa la intervención"104.

4. Por último, en los casos en los que el anestesista abandona el quirófano durante el transcurso de una operación, como ocurre en el supuesto resuelto por la STS 4-111991 (RJ 1991/6021), entre otras muchas, Gómez Rivero entiende que la responsabilidad del cirujano que continúa la operación debe discurrir por los cauces propios de un delito de acción, "y ello porque también ahora lo que convierte en contraria a Derecho la conducta del médico es ya su propia actuación en condiciones que no garantizan la seguridad del enfermo; en otras palabras, el injusto de su conducta consiste en que actúa en condiciones en las que le está vetado hacerlo. Y en esto consiste precisamente el injusto de un delito de acción"105.

\section{Conclusiones}

La aplicación adecuada del criterio de la causalidad, adoptado aquí para diferenciar entre conducta activa y omisiva (con un matiz claramente pragmático)

103 Gómez Rivero, Carmen, La responsabilidad penal del médico, cit., p. 351.

104 Gómez Rivero, Carmen, La responsabilidad penal del médico, cit., p. 347.

105 Gómez Rivero, Carmen, La responsabilidad penal del médico, cit., p. 349. 
sirve para poner de manifiesto los errores que presenta la que hemos denominado teoría de la "contemplación global" de la intervención médica. Desde mi punto de vista resulta rechazable la solución que se propone en los casos de "error de diagnóstico". En mi opinión, en los casos comentados, como en muchos supuestos de "error en el diagnóstico", la conducta penalmente relevante del médico no es activa sino omisiva. Evidentemente, diagnosticar supone una acción, consistente en emitir una valoración del estado del paciente y de la posible evolución de la enfermedad, lo cual supone observar al paciente y realizar las pruebas que se estimen convenientes, pero esto no nos dice nada sobre su calificación jurídica en uno u otro sentido. Simplemente está constatando una realidad que se dará en el $99 \%$ de los casos, y es que nos encontramos ante un realización positiva, que implica un movimiento y una acción, por parte de un sujeto. Pero el término "acción" que nos interesa desde el punto de vista penal viene definido por algo distinto a esa observación exterior. Es necesario poner esa acción humana en relación con el resultado lesivo y preguntarnos si es causa material (siguiendo un juicio naturalístico) o no de aquél. Pues bien, el diagnosticar no desencadena el curso causal (desde un punto de vista estrictamente naturalístico) que lleva al resultado lesivo para el bebé en el primer caso y a la muerte en el segundo. En el primer caso, la falta de oxigenación que sufre el feto se debe al propio proceso anómalo que presenta ese parto en cuestión. La madre no da a luz porque la posición del feto, con el cordón umbilical enrollado en el cuello, impide un desarrollo normal del alumbramiento sin ayuda externa. Pero el diagnóstico de un cólico nefrítico y el tratamiento posterior acorde con dicho diagnóstico no coadyuva físicamente al acontecimiento. Gráficamente, el médico que se equivoca en el diagnóstico no obstaculiza materialmente la salida del feto. Por lo tanto, no puede decirse que esa conducta cause el resultado lesivo, y si no existe causalidad no se puede decir que esa sea una conducta activa. La conducta relevante penalmente es la omisión que resulta del diagnóstico equivocado, es decir, la acción que se deja de hacer por una apreciación incorrecta del estado de la paciente: la atención al parto en la forma que las circunstancias exigían, posiblemente a través de una cesárea. La cuestión que habría que dirimir a continuación es si a esa omisión se le puede atribuir jurídicamente el resultado lesivo, es decir, si se puede hablar de comisión por omisión. Siguiendo la teoría de la creación o incremento del riesgo podría decirse que nos encontramos ante una comisión por omisión. Sería de aplicación aquí la siguiente reflexión de Sılva Sánchez: "La imputación del resultado por vía omisiva adquiere significado cuando el método alternativo empleado es inocuo pero su aplicación ha bloqueado la aplicación de métodos convencionales que ex ante aparecían como eficaces (si no, no habría siquiera omisión imprudente)"106. Por lo tanto, comparto la solución del TS, la calificación de la conducta imprudente del médico de comisión por omisión, pero no

106 Cfr. Silva Sánchez, Jesús María, Medicinas alternativas e imprudencia médica, Barcelona, Bosch, 1999, p. 84. 
los argumentos que utiliza, que ciertamente suponen confundir infracción del cuidado debido con omisión de la acción debida. No obstante, en la primera de las sentencias comentadas, el TS da la clave para entender correctamente la solución aquí expuesta: "(...) y en definitiva, omitió atender un parto en el momento en el que todos los síntomas lo hacían necesario". Todo lo anterior no quiere decir que los supuestos de "error en el diagnóstico" se deban calificar siempre de conductas omisivas. En el primer caso, el diagnóstico concluye que los dolores sufridos por la embarazada son sintomáticos de un cólico nefrítico, lo cual da lugar a que se le aplique un tratamiento que, por lo que se puede desprender de la sentencia, es inocuo para la salud de la paciente y para la del feto, y no interfiere en el proceso del parto. Ese tratamiento no incide en el curso causal ya existente. Ahora bien, si el tratamiento aplicado a partir del diagnóstico incidiese causalmente en el proceso del parto, a modo de barrera, incrementando físicamente las dificultades para la expulsión del feto, entonces sí podríamos decir que la conducta imprudente del médico es activa. No sería algo distinto a inyectar un fármaco a la embarazada para impedir las contracciones, la dilatación y, por lo tanto, el parto natural.

Precisamente, el criterio de la causalidad es el que nos permite afirmar que en los supuestos en los que el médico prescribe un fármaco al que es alérgico el paciente, sin percatarse de tal situación porque no le pregunta ni consulta su historial clínico, inyectándoselo, nos encontramos ante conductas activas, y no omisivas, porque la conducta que desencadena el curso causal desde un punto de vista naturalístico que termina por desembocar en la muerte del paciente no es la ausencia de una pregunta ${ }^{107}$ sino la prescripción y, finalmente, la inyección o la toma del fármaco por parte del paciente. Lo mismo se puede decir en relación con el tema de las transfusiones.

Por lo que respecta a la conducta del anestesista que se ausenta del quirófano, habrá que estar al caso concreto, pues si la causa de la muerte del paciente es la difusión de un agente anestésico en mayor cantidad de la debida, el cerrar y abrir un grifo equivocado, el intubar incorrectamente al paciente, por ejemplo, la conducta del anestesista será activa. Ahora bien, si el suministro de anestesia es correcto y la operación se desarrolla normalmente, pudiendo surgir un imprevisto debido a una pérdida de caudal sanguíneo, 0 a que el paciente entre en un estado de shock cuyo origen no pueda ser reconducido a la aplicación del agente anestésico, entonces la ausencia del anestesista de la sala dará lugar a calificar su conducta como omisiva, igual que si se encontrase en la sala pero no realizase la labor de vigilancia de las constantes vitales del paciente a través de los monitores. Se trata aquí de omitir la acción debida, por una falta de cuidado. Por su parte, la responsabilidad del cirujano parece reconducirse a la comisión por omisión, porque permitiendo la ausencia del anestesista asume su posición y no vigila las constantes vitales del paciente, lo cual le

107 Sobre esta cuestión Gómez Rivero, CARmen, La responsabilidad penal del médico, cit., p. 351 s. 
permitiría percatarse del empeoramiento de la situación y adoptar la acción necesaria para corregir el curso de los acontecimientos y evitar el resultado letal.

No obstante, no se puede ignorar que las soluciones propuestas desde la primera de las posturas presentadas suponen, en ocasiones, una secuenciación excesiva de la intervención del médico. Así, por ejemplo, en relación con las intervenciones quirúrgicas en las que el cirujano se deja olvidada una gasa en el cuerpo del paciente, el dividir la conducta del médico entre la introducción de la gasa y la extracción de la misma es una exageración. El médico lleva a cabo múltiples actuaciones sucesivas a lo largo de una intervención quirúrgica que forman parte de un acto global, consistente en operar. Al igual que se distingue entre introducir la gasa y extraer la gasa también se podría establecer como referente de la valoración penal la conducta de "operar sin llevar a cabo el cuidado debido", es decir, una conducta activa.

\section{Bibliografía}

Alastuey Dobón, María del Carmen, “Delitos de comisión por omisión en la jurisprudencia del Tribunal Supremo", en: ADPCP 1992, 969-1021.

Arroyo Zapatero, Luis, La protección penal de la seguridad en el trabajo, pról. Barbero Santos, Marino, Madrid, Servicio Social de Higiene y Seguridad del Trabajo, 1981.

Bacigalupo Zapater, Enrioue, Principios de Derecho Penal. Parte General, 5. a ed., Madrid, Akal, 1998.

Сobo Del Rosal, Manuel (dir.), Comentarios al Código penal, Madrid, Edersa, t. I, 1999: arts. 1-18.

Corcoy Bidasolo, Mirentxu, El Delito imprudente. Criterios de imputación del resultado, pról. Mir Puig, Santiago, Barcelona, PPU, 1989.

Córdoba Roda, Juan/Rodríguez Mourullo, Gonzalo, Comentarios al Código Penal, t. I, Barcelona, Ariel, 1972.

Cuadrado Ruiz, M. a Ángeles, "La comisión por omisión como problema dogmático", en: ADPCP 1997, 387-456.

- "La posición de garante", en: ADPCP 2000, 11-68.

De Vicente Remesal, Javier/Díaz y García Conlledo, Miguel, "Autoría o participación en determinados supuestos de 'vigilancia' (Comentarios a la STS 21-2-1989) (Pte. Bacigalupo Zapater)", en: PJ 27-1992 (comentario tercero), 189-216.

Díaz y García Conlledo, Miguel, La autoría en Derecho Penal, pról. Luzón Peña, DiegoManuel, Barcelona, PPU, 1991.

- "Omisión de impedir delitos no constitutiva de participación por omisión: ¿un caso de dolo alternativo?", en: PJ 24-1991, 203-220 
Dopico Gómez-Aller, Jacobo, Omisión e injerencia en Derecho penal, pról. GómezBenítez, José Manuel, Valencia, Tirant lo Blanch, 2006.

Durán Seco, Isabel, La coautoría en Derecho Penal: aspectos esenciales, León, Secretariado de publicaciones y medios audiovisuales de la Universidad de León, 2003.

García Mosouera, Marta, La estafa de seguro, pról. De Vicente Remesal, Javier, Madrid, La Ley, 2006.

Gimbernat Ordeig, Enrioue, "Sobre los conceptos de omisión y de comportamiento", en: ADPCP 1987, 579-607.

- "Causalidad, omisión e imprudencia", en: ADPCP 1994, 5-60.

- "La omisión impropia en la dogmática penal alemana. Una exposición", en: ADPCP 1997, 5-112.

- "El delito de omisión impropia", en: RDPCr 4-1999, 525-553.

Gómez Pavón, PILAR, "La responsabilidad del médico por omisión", en: PJ 40-1995, 287-305.

Gómez Rivero, Carmen, La responsabilidad penal del médico, Valencia, Tirant lo Blanch, 2003.

Hava García, Esther, La imprudencia médica, Valencia, Tirant lo Blanch, 2001.

Huerta Tocildo, Susana, Problemas fundamentales de los delitos de omisión, Madrid, Ministerio de Justicia e Interior, Centro de Publicaciones, 1987.

Jakobs, Günther, Derecho Penal, Parte General, Fundamentos y teoría de la imputación,

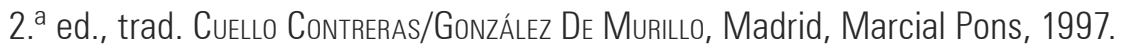
Jescheck, Hans Heinrich/Weigend, Thomas, Tratado de Derecho Penal. Parte General, trad. 3. ${ }^{a}$ ed. y adiciones Mir Puig/Muñoz Conde, Barcelona, Bosch, 1981; trad. 5. ${ }^{\text {a }}$ ed. Olmedo Cardenete, Granada, Comares, 2002.

Jorge Barreiro, Agustín, La imprudencia punible en la actividad médico-quirúrgica, Madrid, Tecnos, 1990.

Kaufmann, Armin, Dogmática de los delitos de omisión, trad. de la 2. ${ }^{a}$ ed. alemana Cuello Contreras/Serrano González De Murillo, Madrid, Marcial Pons, 2006.

Lascurain Sánchez, Juan Antonio, La protección penal de la seguridad e higiene en el trabajo, pról. Rodríguez Mourullo, Gonzalo, Madrid, Civitas, 1994.

Luzón Peña, Diego-Manuel, "Ingerencia, comisión por omisión y omisión de socorro (Comentario a la STS 24-4-1974)", en: RDCir 1974, 269-273.

- "Omisión de socorro: distinción entre omisión propia e impropia (Comentario a la STS 3-3-1980)", en: RDCir 1980, 386-388.

- "Autoría e imputación objetiva en el delito imprudente: valoración de las aportaciones causales (Comentario a la STS 27-1-1984)", en: RDCir 1984. 
- "La participación por omisión en la jurisprudencia reciente del TS", en: PJ 2-1986, 73-92.

- "La 'determinación objetiva del hecho'. Observaciones sobre la autoría en delitos dolosos e imprudentes de resultado", en: ADPCP 1989, 889-913.

- Derecho Penal de la Circulación. Estudios de la jurisprudencia del Tribunal Supremo, 2. a ed., Barcelona, PPU, 1990.

Curso de Derecho Penal. Parte General, Universitas, Madrid, 1996

- Lecciones de Derecho Penal. Parte General, 3. ${ }^{a}$ ed., Valencia, Tirant lo Blanch, 2015.

- “Omisión impropia o comisión por omisión. Cuestiones nucleares: imputación objetiva sin causalidad, posiciones de garante, equivalencia (concreción del criterio normativo de la creación 0 aumento de peligro o riesgo) y autoría 0 participación", en: Libertas, Revista de la Fundación Internacional de Ciencias Penales 6-2017, 145-271

luzón Peña, Diego-Manuel/Díaz y García Conlledo, Miguel, "Objektive positive Tatbestimmung und Tabestandsverwirklichung als Täterschaftsmerkmale", en: FS- Roxin, 2001.

- “Determinación objetiva y positiva del hecho y realización típica como criterios de autoría", en: RDPC 2003-2, 89-128.

Maurach, Reinhart/Gössel, Karl Heinz/Zipf, Heinz, Derecho Penal. Parte General 2: Formas de aparición del delito y las consecuencias jurídicas del hecho, trad. de

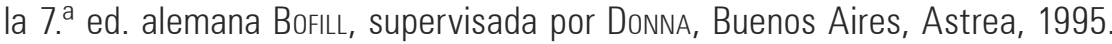

Mir Puig, Santiago, Derecho Penal. Parte General, 10. ${ }^{a}$ ed., Barcelona, Reppertor, 2015

Muñoz Conde, Francisco/García Arán, Mercedes, Derecho Penal. Parte General, 9. a ed. Valencia, Tirant lo Blanch, 2015.

Octavio De Toledo y Ubieto, Emilio/Huerta Tocildo, Susana, Derecho penal. Parte General: Teoría jurídica del delito, 2. ${ }^{a}$ ed., Madrid, Castellanos, 1986.

Olaizola Nogales, Inés, El delito de cohecho, pról. Díaz y García Conlledo, Miguel, Valencia, Tirant lo Blanch, 1999.

Paredes Castañón, José Manuel, El riesgo permitido en Derecho penal (Régimen jurídico-penal de las actividades peligrosas), Madrid, Ministerio de Justicia e Interior, Centro de Publicaciones, 1995.

Paredes Castañón, José Manuel/Rodríguez Montañés, Teresa, El caso de la colza: responsabilidad penal por productos adulterados o defectuosos, pról. Luzón Peña, Diego-Manuel, Valencia, Tirant lo Blanch, 1995.

Quintero Olivares, Gonzalo/Morales Prats, Fermín/Prats Canut, Josep Miquel, Manual de Derecho Penal. Parte General, 3. ${ }^{a}$ ed., Pamplona, Aranzadi, 2002. 
Rodríguez Mourullo, Gonzalo, La omisión de socorro en el Código Penal, pról. Córdoba Roda, Juan, Madrid, Tecnos, 1966.

Rodríguez Vázouez, Virgilıo, Responsabilidad penal en el ejercicio de actividades médico-sanitarias, pról. De VIcente Remesal, Javier, Madrid, Marcial Pons, 2012.

Roso Cañadillas, Raquel, Autoría y participación imprudente, pról. Luzón Peña, DiegoManuel, Granada, Comares, 2002.

Roxin, Claus, Allgemeiner Teil, t. I: Grundlagen. Der Aufbau der Verbrechenslehre, 3. ${ }^{\text {a }}$ ed., München, Beck, 1997.

- Derecho penal, Parte General, t. I: Fundamentos. La estructura de la teoría del delito, trad. de la 2. ${ }^{a}$ ed. alemana y notas Luzón Peña/Díaz y García Conlledo/De Vicente Remesal, Madrid, Civitas, 1997.

- Autoría y dominio del hecho en Derecho penal, 2. ${ }^{\text {a }}$ ed., trad. de la 7. ${ }^{\text {a }}$ ed. alemana, Cuello Contreras/Serrano Gonzalo de Murillo, pról. Cobo Del Rosal, Manuel, Madrid, Marcial Pons, 2000.

Schönke, Adolf/Schröder, Horst, StGB, Kommentar, 27. a ed., a cargo de Lenckner, Theodor/Cramer, Peter/Eser, Albin/Stree, Walter/Elsele, Jörg/Heine, Günter/Perron, Walter/Steernberg-Lieben, Detlev/Schittenhelm, München, Beck, 2006.

Silva Sánchez, Jesús María, El delito de omisión. Concepto y sistema, pról. Mir Puig, SANTIAGo, Barcelona, Bosch, 1986.

- "La responsabilidad penal del médico por omisión", en: Mir Puig, Santiago (ed.), Avances de la Medicina y Derecho Penal, Barcelona, PPU, 1988.

- “'Comisión' y 'omisión'. Criterios de distinción”, en: CuadDJ 1994-XXIII, 57-69.

- "Aspectos de la responsabilidad penal por imprudencia del médico anestesista. La perspectiva del Tribunal Supremo", en: DS 2-1994, 41-58.

- El nuevo Código penal: cinco cuestiones fundamentales, Barcelona, Bosch, 1997.

- Medicinas alternativas e imprudencia médica, Barcelona, Bosch, 1999.

- "Omisión”, en: Luzón Peña, Diego-Manuel (dir.), EPB, Granada, Comares, 2002.

Stratenwerth, Günter, Derecho Penal. Parte General, I: El hecho punible, trad. Romero, Madrid, Edersa, 1982.

- Strafrecht, Allgemeiner Teil, I: Die Straftat, 4. ${ }^{\text {a }}$ ed., München, Heymanns, 2000.

Villacampa Estiarte, Carolina, Responsabilidad penal del personal sanitario. Atribución de responsabilidad penal en tratamientos médicos efectuados por diversos profesionales, Pamplona, Aranzadi, 2003.

Vives Antón, Tomás S. (coord.), Comentarios al Código Penal de 1995, t. I y II., Valencia, Tirant lo Blanch, 1996.

Zugaldía Espinar, José Miguel/Pérez Alonso, Esteban Juan, Derecho penal. Parte General, 2. ${ }^{a}$ ed.,Valencia, Tirant lo Blanch, 2004. 